OPEN ACCESS

Edited by:

Andreas Frick,

Institut National de la Santé et de la Recherche Médicale, France

Reviewed by:

Pascal Darbon,

Université de Strasbourg, France Xin Wang,

Stanford University and Howard Hughes Medical Institute, USA

${ }^{*}$ Correspondence: Maria Lisa Rossi, Dipartimento di Scienze della Vita e Biotecnologie, Ferrara University, Via Luigi Borsari, 46 Ferrara, Italy rsm@unife.it

Received: 06 January 2015 Accepted: 09 June 2015

Published: 23 June 2015

Citation:

Martini M, Canella R, Rubbini G, Fesce $R$ and Rossi ML (2015)

Sensory transduction at the frog semicircular canal: how hair cell membrane potential controls junctional transmission.

Front. Cell. Neurosci. 9:235.

doi: $10.3389 /$ fncel.2015.00235

\section{Sensory transduction at the frog semicircular canal: how hair cell membrane potential controls junctional transmission}

\author{
Marta Martini ${ }^{1}$, Rita Canella ${ }^{1}$, Gemma Rubbini ${ }^{1}$, Riccardo Fesce ${ }^{2}$ and Maria Lisa Rossi ${ }^{1 \text { * }}$ \\ ${ }^{1}$ Dipartimento di Scienze della Vita e Biotecnologie, Ferrara University, Ferrara, Italy, ${ }^{2}$ Centre of Neuroscience and DISTA, \\ Insubria University, Varese, Italy
}

At the frog semicircular canals, the afferent fibers display high spontaneous activity (mEPSPs), due to transmitter release from hair cells. mEPSP and spike frequencies are modulated by stimulation that activates the hair cell receptor conductance. The relation between receptor current and transmitter release cannot be studied at the intact semicircular canal. To circumvent the problem, we combined patch-clamp recordings at the isolated hair cell and electrophysiological recordings at the cytoneural junction in the intact preparation. At isolated hair cells, the $\mathrm{K}$ channel blocker tetraethylammonium (TEA) is shown to block a fraction of total voltage-dependent $\mathrm{K}$-conductance (IKD) that depends on TEA concentration but not on membrane potential $\left(V_{\mathrm{m}}\right)$. Considering the bioelectric properties of the hair cell, as previously characterized by this lab, a fixed fractional block of IKD is shown to induce a relatively fixed shift in $V_{\mathrm{m}}$, provided it lies in the range -30 to $-10 \mathrm{mV}$. The same concentrations of TEA were applied to the intact labyrinth while recording from single afferent fibers of the posterior canal, at rest and during mechanical stimulation. At the peak of stimulation, TEA produced increases in $\mathrm{mEPSP}$ rate that were linearly related to the shifts produced by the same TEA concentrations $(0.1-3 \mathrm{mM})$ in hair cell $V_{\mathrm{m}}(0.7-5 \mathrm{mV})$, with a slope of $29.8 \mathrm{~Hz} / \mathrm{mV}$. The membrane potential of the hair cell is not linearly related to receptor conductance, so that the slope of quantal release vs. receptor conductance depends on the prevailing $V_{\mathrm{m}}(19.8 \mathrm{~Hz} / \mathrm{nS}$ at $-20 \mathrm{mV} ; 11 \mathrm{~Hz} / \mathrm{nS}$ at $-10 \mathrm{mV})$. Changes in mEPSP peak size were negligible at rest as well as during stimulation. Since ample spatial summation of mEPSPs occurs at the afferent terminal and threshold-governed spike firing is intrinsically nonlinear, the observed increases in mEPSP frequency, though not very large, may suffice to trigger afferent spike discharge.

Keywords: semicircular canal, hair cell currents, TEA effect, mEPSP release, membrane potential, receptor conductance, sensory processing

\section{Introduction}

A number of different approaches have been used to study the function of vestibular hair cells in processing the mechanical stimulus and producing the activation of the first afferent neuron. No experimental approach has been able, so far, to quantitatively correlate the single steps of this complex sensory processing. The electrophysiological 
(Ohmori, 1985; Holton and Hudspeth, 1986; Crawford et al., 1991; Martini et al., 2000, 2009, 2013; Ricci et al., 2003) and structural properties (Corey and Hudspeth, 1979; Gillespie and Müller, 2009; Kim and Fettiplace, 2013; for a review see Fettiplace, 2009) of the transduction channels, and the resulting receptor currents and receptor potentials, have been extensively studied in several hair cell types. The complex interplay of ionic currents at the isolated hair cell has also been described in detail (Housley et al., 1989; Lang and Correia, 1989; Masetto et al., 1994; Rennie and Correia, 1994; Brichta et al., 2002; Catacuzzeno et al., 2003; Martini et al., 2009), and a number of categories of sensory units have been discriminated, based on electrophysiological properties and spike firing patterns (Wilson and Melvill Jones, 1979; Goldberg, 1991; Goldberg and Brichta, 2002; Pfanzelt et al., 2008). As regards the cellular and junctional mechanisms in the intact vestibular apparatus, direct information on hair cell properties has been obtained through intracellular recording from amphibian saccular hair cells (Bracho and Budelli, 1978) at rest, whereas quantal emission and spike discharge in single afferent units, both at rest and during mechanical stimulation, have been thoroughly characterized by recording from the frog posterior semicircular canal, close to the cytoneural junction (Housley et al., 1989; Rossi et al., 1989, 1994, 2010). Only type II hair cells are present in this preparation, and they are in the physiological milieu, with the apical membrane in contact with the endolymph and the basolateral membrane surrounded by a perilymph-like solution. However, the presence of the cupula prevents intracellular recordings from single hair cells, so that their actual resting membrane potential and the size of the receptor potential during canal stimulation are unknown. The semicircular canal cupula-endolymph system is tuned for low-frequency signals, so that the type and kinetics of voltage-dependent channels in the hair cell may differ from those previously described in saccular or cochlear hair cells.

In this study we attempt to partially circumvent the gap between single-cell and synaptic studies. The idea is to find an experimental tool to produce a change in hair cell membrane potential of known magnitude and investigate the corresponding effects on synaptic activity. We show here that the K-channel blocker, tetraethylammonium (TEA), produces a fixed, voltage independent, fractional block of potassium current, so that its action on hair cell membrane potential, at a given concentration, can be mathematically predicted based on the complete characterization of the electrical properties of the isolated hair cell and of its ionic conductances, carried out in previous works (Martini et al., 2000, 2009, 2013), and experimentally verified at the isolated hair cell. The magnitude of the receptor conductance that would produce similar shifts can be estimated. In parallel, the effects of the same concentrations of TEA on synaptic activity in the intact preparation are measured in the experiments here presented, by intracellularly recording close to the posterior canal cytoneural junction at rest and during rotation. Thus, presynaptic potential and receptor conductance changes can be quantitatively correlated with the changes in the intensity of quantal release at the cytoneural junction and spike firing at the first afferent neuron.

\section{Materials and Methods}

Frog labyrinth preparation, stimulation and recording procedures have been described in detail previously, both for patch clamp experiments (Martini et al., 2000, 2009, 2013), and intracellular recordings (Rossi et al., 1989, 1994).

All procedures for animal handling and surgery were approved by the Animal Care and Use Committee of the University of Ferrara. The experiments were performed on wild frogs (Rana esculenta, 25-50 g body weight) purchased from authorized dealers.

The frogs were anesthetized in tricaine methane sulfonate solution ( $1 \mathrm{~g} / \mathrm{l}$ in tap water) and subsequently decapitated.

\section{Patch Clamp Experiments Cell Preparation}

Dissection of the two labyrinths was performed in a solution of the following composition (mM): $120 \mathrm{NaCl}, 2.5 \mathrm{KCl}$, 0.5 EGTA, 5 4-2-hydroxyethyl-1-piperazineethanesulfonic acid (HEPES), 3 glucose, 20 sucrose. The final $\mathrm{pH}$ was 7.2 and the osmolality $256 \mathrm{mOsmol} / \mathrm{kg}$. The six ampullae were treated for a period of 10-20 s with subtilisin A, type VIII $(50 \mu \mathrm{g} / \mathrm{ml}$, Sigma); the protease was thereafter blocked by trypsin inhibitor type II-S (Sigma) added to the dissection solution (final concentration $0.7 \mathrm{mg} / \mathrm{ml}$ ). The ampullae were transferred to the experimental chamber (500 $\mu$ l volume), submerged in the standard extracellular solution $(\mathrm{mM}): 120 \mathrm{NaCl}, 2.5 \mathrm{KCl}$,

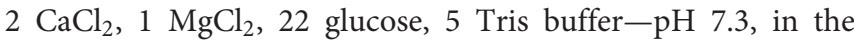
presence of the trypsin inhibitor (osmolality $260 \mathrm{mOsmol} / \mathrm{kg}$ ). Hair cells were mechanically dissociated from the ampullae by gently scraping the epithelium with a fine forceps. The protease inhibitor was eventually washed out before starting with electrophysiology. The glass bottom of the experimental chamber was coated with chloro-tri- $n$-butyl-silane to prevent cell sticking.

Cells were viewed through a TV monitor connected to a contrast enhanced video camera (T.I.L.L. Photonics, Planegg, Germany) and continuously superfused with the extracellular solution. The camera was coupled to an inverted microscope (Olympus IMT-2, Tokyo, Japan) equipped with a 40x Hoffman modulation contrast system.

\section{Whole Cell Recording}

Macroscopic currents were recorded at room temperature, within $1 \mathrm{~h}$ after cell dissociation, by using the patch-clamp technique (EPC-7, List-Electronic, Darmstadt, Germany) in the "whole-cell" configuration. Pipettes were pulled from $50 \mu \mathrm{l}$ glass capillaries (Drummond, Broomall, PA, USA) and firepolished to a pipette resistance of 4-5 $\mathrm{M} \Omega$. The pipette was filled with the following (mM): $110 \mathrm{KCl}, 2 \mathrm{MgCl}_{2}, 8$ ATP (K salt), 0.1 GTP (Na salt), 5 EGTA-NaOH, 10 Hepes$\mathrm{NaOH}$ (pH 7.2; $256 \mathrm{mOsmol} / \mathrm{kg})$. Cadmium chloride $(0.2 \mathrm{mM})$ was used as blocker of voltage-dependent calcium channels, when needed. It was applied by rapidly changing (typically 
$<50 \mathrm{~ms}$ ) the external solution by horizontally moving a multi-barrelled perfusion pipette positioned in front of the recorded cell by means of a computer-controlled stepping motor. The same perfusion technique was employed to apply TEA-Cl $(0.05-30 \mathrm{mM})$ or a mix of $\mathrm{Cd}^{2+}$ and TEA solution.

Isolated hair cells exhibited high membrane resistance $(>1 \mathrm{G} \Omega$ ) at $-70 \mathrm{mV}$. These values indicate that no major conductances, such as hyperpolarization-activated currents or depolarizing currents due to transduction channels possibly open at rest, were significantly active in the native hair cell. Series resistance ranged 8-22 M $\Omega$. The cell capacitance and series resistance were electronically compensated (50-75\%) before running each voltage-clamp protocol. The uncompensated series resistance component introduced an error in the applied voltage command: such error was limited to $10-12 \mathrm{mV}$ when the largest currents were recorded and was not corrected for. Leak was measured near resting potential with a $10 \mathrm{mV} \times$ $15 \mathrm{~ms}$ hyperpolarizing pulse and subsequently subtracted, assuming a linear behavior, in correcting current recordings off-line. Currents were low-pass filtered at $5 \mathrm{kHz}$ and acquired on-line at $10 \mathrm{kHz}$ with pClamp hardware and software (pClamp 9.1 and Digidata 1322A interface; Axon Instruments, Union City, CA, USA). Data were analyzed off-line by using pClamp 9.1 software. They were not corrected for the liquid junction potential, estimated to be about $+4 \mathrm{mV}$ under our standard recording conditions (Martini et al., 2009).

\section{Intracellular Recordings}

Experiments were performed on the isolated and intact frog labyrinth. The frog head was pinned down at the bottom of the dissection chamber and submerged in a dissection solution containing (mM): $120 \mathrm{NaCl}, 2.5 \mathrm{KCl}, 2 \mathrm{CaCl}_{2}, 1 \mathrm{MgCl}_{2}, 5$ glucose,

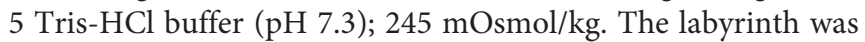
isolated. The posterior canal was exposed with its nerve in the right half of the frog head; then the labyrinth, protected by the remaining bone, was separated from the head, transferred to a small Perspex chamber mounted at the center of a small turntable and fixed to the bottom of the chamber. The turntable assembly, designed for electrophysiological examination of the labyrinthine function, included a custom-made miniaturized microelectrode amplifier (0-5 kHz bandwidth) and was driven by a servomotor controlled by a function generator. The preparation was accurately positioned so that the posterior canal lay in the plane of table rotation. Mechanical stimulation experiments were performed by subjecting the canal to a sinusoidal angular velocity stimulus at $0.1 \mathrm{~Hz}$, peak acceleration $12.5^{\circ} / \mathrm{s}^{2}$. Intracellular recordings were obtained at rest and during rotation using glass microelectrodes (30-40 $\mathrm{M} \Omega$ resistance), filled with $3 \mathrm{M} \mathrm{KCl}$, inserted into the posterior nerve within about $500 \mu \mathrm{m}$ from the synapse. The recorded potentials were transferred through low-noise sliding contacts to the oscilloscope, and stored on tape. Recordings were performed from a single fiber before and after gently substituting the TEA-containing medium for the control solution. The afferent discharge recorded from single fibers of the posterior nerve was examined off-line both in terms of spike frequency and of frequency and waveform of miniature excitatory post synaptic potentials (mEPSPs, see below, "Quantal Analysis" Section).

\section{Quantal Analysis}

Recordings from the primary afferent axon at the frog posterior semicircular canal display quantal synaptic events (mEPSPs) (Rossi et al., 1994), which occur at a variable rate and generate action potential firing at variable frequency. At rest, about $20-30 \%$ of the units do not display any spike and when the spikes are present, their rate very rarely exceeds $10 /$ s. When the preparation is sinusoidally rotated, both mEPSP and spike rates are clearly modulated by rotational acceleration.

We developed in the past an original procedure to analyze quantal transmitter release at the cytoneural junction: mEPSP rates of occurrence above 100/s can be measured (Rossi et al., $1989,1994)$. The procedure, which was previously used to analyze cytoneural transmission in various experimental conditions, is based on the following steps:

(i) identification of the general waveform of the mEPSP, by means of fits to the spectral composition and autocorrelation of synaptic recordings: 2nd- to 5th-order autoregressive fits of the autocorrelation are used to estimate the gammadistribution function best-fitting the "average" event waveform: $w(t)=h \cdot \frac{(\beta t)^{\gamma}}{\Gamma(\gamma+1)} \cdot \exp (-\beta t)$, where $h$ is a size factor $(\mathrm{mV})$, $\beta$ is a rate constant $\left(\mathrm{s}^{-1}\right), \gamma$ is a numeric coefficient that determines the shape of the waveform (from a single exponential, for $\gamma=0$, towards a Gaussian bell, for $\gamma>10$ ), and $\Gamma$ is Euler's gamma function; (ii) computation of a Wiener filter from such elementary waveform; (iii) application of the Wiener filter to turn the noisy electrophysiological junctional trace into a spiky recording; and (iv) automated counting of the events.

Often the mEPSP frequencies were very high in the experiments here reported (several hundreds/s), and simple Wiener filtering, after deleting the spikes, was insufficient to accurately measure the rate of occurrence of mEPSPs from the noisy recording. We therefore employed a recently developed refinement of the procedure (Rossi et al., 2010), which combines the above mentioned Wiener filtering routine for event detection with least-square-errors optimization of fit and identification of possibly neglected events; this procedure yields the best fitting set of parameters (time of occurrence, $t_{0}$, size factor, $h$, and waveform parameters $\beta$ and $\gamma$ for each event); events with particularly small amplitude or aberrant waveform can be excluded as artifacts.

The sequence of time intervals between successive events was translated into a continuous function that described the rate of occurrence of mEPSPs as a function of time. An example of the power of this analysis is shown in Figure 1.

This approach could be used to measure high event rates (mean mEPSP rate $400 / \mathrm{s}$, instantaneous rate up to $800 / \mathrm{s}$ ), even in the presence of quite variable size and waveforms of the individual events.

In the presence of spikes, the latter were automatically detected, counted and subtracted from the recording before 
A

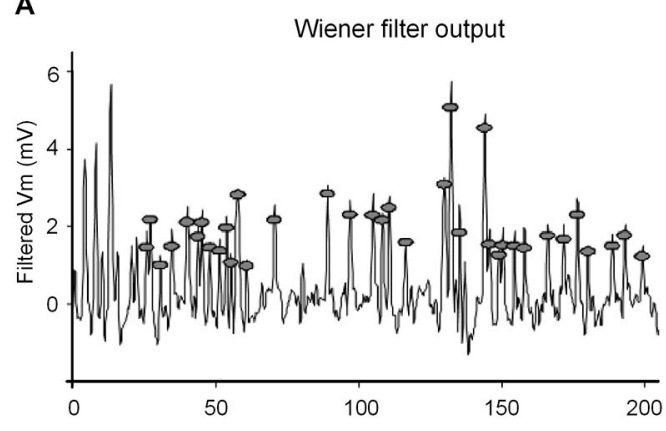

B

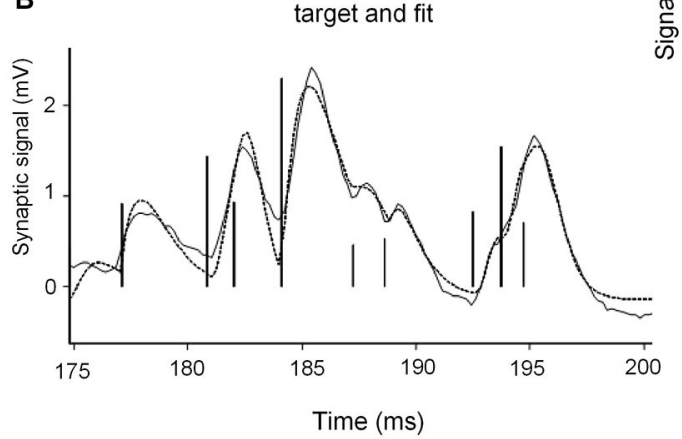

FIGURE 1 A snapshot of the computer display during fitting

(A) A section of the recording (200 ms) after Wiener filtering. The first $25 \mathrm{~ms}$ overlap the previous section and are not considered for fitting. Gray circles highlight the peaks in Wiener filter output, which are considered as indicators of the occurrence of mEPSPs. (B) The subsection of the record currently being fitted: the continuous line reproduces the data, the dotted line is the fit obtained by convolving the delta functions corresponding to the occurrence
C

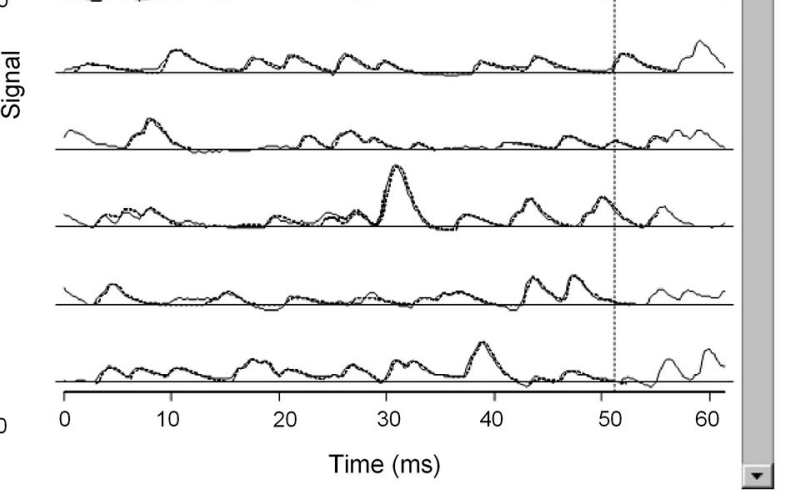

and size of each mEPSP (vertical bars) by analytic gamma-functions (see Section Materials and Methods), with best fitting duration $(\boldsymbol{\beta})$ and shape $(\boldsymbol{\gamma})$ parameters. (C) Continuously updated display of the overall fit: continuous and dotted lines reproduce the signal and fit; in the original display on the screen, different colors illustrate the sections just fit and currently being fitted (here, the fourth line); the cursor on the right hand side monitors the progress of fitting along the datafile. proceeding with the analysis of mEPSPs. Subtraction of each spike left a $3 \mathrm{~ms}$ portion of the recording which could not be corrected and analyzed. This implied that some elementary events were unavoidably missed. Analysis of mEPSP rates at times immediately preceding or following the spikes, the observation that momentary rates up to $800 \mathrm{mEPSPs} / \mathrm{s}$ could be occasionally estimated in spikefree portions of the recordings, and the consideration that the coincidence of several mEPSPs must occur to generate a spike, led us to estimate that 4-6 mEPSPs were missed for each subtracted spike. Therefore, mEPSP counts were corrected by adding five mEPSPs in the $3 \mathrm{~ms}$ interval corresponding to each subtracted spike (Rossi et al., 2010).

In some experiments tricaine $10^{-4} \mathrm{M}$ was added to the bath. The effect was complete within 2-3 min: both the resting and mechanically evoked spike discharges were abolished. On the contrary, mEPSP emission rate remained unaltered and regularly modulated by the excitatory and inhibitory phases of the sinusoidal rotation. The effect of tricaine was completely and rapidly reversible upon returning to the normal Ringer solution. This property was also used to demonstrate the reliability of the mEPSP automated counting (and spike subtraction) procedure before and after tricaine (Rossi et al., 2010).
The analysis of mEPSP size was performed on the peak amplitude of events; in particular, the time to the peak is $t_{p}=\gamma / \beta$ and the peak amplitude of the event waveform is:

$P=w\left(t_{p}\right)=h \cdot \frac{\left(\beta t_{p}\right)^{\gamma}}{\Gamma(\gamma+1)} \exp \left(-\beta t_{p}\right)=h \cdot \frac{\gamma^{\gamma}}{\Gamma(\gamma+1)} \exp (-\gamma)$

(Rossi et al., 1994).

All routines for quantal analysis have been developed in Matlab software environment (Version 5.0.1 or 10a. The MathWorks, Natick, MA, USA).

\section{Minimal Electrical Model of the Hair Cell}

The delayed outward "non-inactivating" current, IKD, in the frog hair cell was assumed to obey a Hodgkin-Huxley paradigm, controlled by a voltage-dependent activation parameter, $a$. Previous work has shown that the time constant of IKD activation is in the order of $1 \mathrm{~ms}$ (Martini et al., 2009), i.e., much faster than the changes in membrane potential produced by rotational stimulation at $0.1 \mathrm{~Hz}$; thus, we might neglect the timedependent transients and concentrate on the steady state value of the activation parameter of IKD, as a function of membrane potential. The parameters of a standard Boltzmann equation fitting IKD conductance over the voltage range of interest 
have been evaluated by fitting the average current waveform evoked in 50 experiments by a sinusoidal voltage command $(-70$ to $-10 \mathrm{mV})$, assuming a potassium ion equilibrium potential ("zero-current potential" for potassium currents, $E_{K}$ ) of $-95 \mathrm{mV}$.

The relevant equations are: $I_{K D}=g_{K D} \cdot\left(V_{\mathrm{m}}-E_{K}\right), g_{K D}=g_{\mathrm{MAX}}$. $\left(1+\exp \left(-\left(V-V_{C}\right) / K_{V}\right)^{-1}\right.$. where $g_{K D}$ and $g_{\text {MAX }}$ indicate the total cell $K D$ conductance at each value of membrane potential $(V)$ and its maximal value, respectively; $V_{C}$ is the "center voltage", i.e., the value at which $g_{K D}$ equals $g_{\mathrm{MAX}} / 2 ; K_{V}$ is a slope parameter that determines the steepness of the dependence of $g_{K D}$ on membrane potential.

The non-voltage-dependent conductances are lumped in our computations into a nominal "leak" current, defined by the parameters $E_{\text {leak }}=-68.92 \mathrm{mV}, g_{\text {leak }}=0.76 \mathrm{nS}$ (Martini et al., 2009).

The delayed potassium current was modeled as a single lumped current, IKD, resulting from the summed voltagedependent potassium current (IKV), calcium current (ICa) and voltage-calcium-dependent potassium current (IKCa); justification for doing so is that the components comprising the compound current behave functionally as a single complex, in which the physiological role of the single components is not easily isolated (Martini et al., 2009); due to the quite slow changes in membrane potential here considered, the transient potassium current (IA) gives a negligible contribution, as it is mostly inactivated at the $-50 \mathrm{mV}$ holding level $\left(h_{A \infty}=0.07\right)$ and its activation and inactivation kinetics proceed at comparable speeds during voltage fluctuations at $0.1 \mathrm{~Hz}$. The voltage dependence of IKD and its inhibition by various TEA concentrations were examined both during a sinusoidal cycle between -70 and $-10 \mathrm{mV}$ and in response to $300-\mathrm{ms}$ voltage steps.

\section{Curve Fitting}

The dose-response curves for inhibition of outward currents were fitted with equations of the form:

$$
I=I_{0} \cdot\left(1-M \cdot\left(\frac{[T E A]}{[T E A]+K_{i}}\right)^{h}\right)
$$

where [TEA] is the concentration tested $(\mathrm{mM}), K_{i}$ is the estimated affinity of the drug $(\mathrm{mM}), M$ is the maximal amount of block and $h$ is Hill's coefficient.

In experiments where the currents were measured in the presence of various concentrations of TEA while the membrane potential was slowly driven along a sinusoidal path, the current blocked by TEA was fitted using the following equation, adapted to introduce the voltage dependence:

$$
I_{T E A}(V,[T E A])=I_{T E A}(V,[\infty]) \cdot\left(\frac{[T E A]}{[T E A]+K_{i}}\right)^{h}
$$

where $K_{i}$ and $h$ have the same meaning as above, and ITEA( $V$, $[\infty])$ represents the maximum current that can be blocked by TEA at each membrane potential value, $V$.

\section{Statistical Analysis}

All data are reported in the text and in the figures as means \pm SE. Comparisons among different conditions were performed by Student's $t$-test (paired $t$-test for paired observations). Values of $P<0.05$ were considered significant. Nonparametric comparisons are not reported: in each experimental series, at least five units were studied for each TEA concentration, by comparing measurements before/after applying TEA in the same unit: the changes were always consistent (decreased current in the hair cell, increased mEPSP frequency), which yields a nonparametric $P=2^{-5}<0.05$ in all comparisons.

\section{Results}

Primary goal of the present work was to identify a pharmacological instrument to selectively block to a known (possibly voltage-independent) extent the potassium currents that physiologically balance the depolarizing transduction current. The IKCa fraction could be indirectly blocked by $\mathrm{Cd}^{2+}$, which impairs calcium inflow, but its effect is difficult to control in order to obtain a continuous dose-response relationship. The wide-spectrum $\mathrm{K}^{+}$channel antagonist, TEA, conversely, is supposed to effectively block the IKCa, and possibly other components with lower potency: we therefore investigated the sensitivity of the different $\mathrm{K}^{+}$channel types of the isolated hair cell to this agent. Figures $\mathbf{2 A , B}$ shows representative tracings of the effect of $2 \mathrm{mM}$ TEA on the compound IKD, evoked in the $0 /+40 \mathrm{mV}$ voltage range; Figures $2 \mathrm{C}-\mathbf{E}$ illustrates that $2 \mathrm{mM}$ TEA has no effect on the calcium-independent IKV, as isolated by blocking IKCa in $0.2 \mathrm{mM} \mathrm{Cd}^{2+}$. In Figure $2 \mathbf{F}$, the inhibition of each current by TEA was normalized to control conditions for each cell. Five to eight cells were tested for each TEA concentration, in the range $0.05-30 \mathrm{mM}$; the effect of TEA was assessed at $+40 \mathrm{mV}$, close to the calcium ion equilibrium potential (as determined from previous analyses of calcium current I/V curves: Martini et al., 2000) to minimize any contamination of IKD amplitude by possible calcium currents (filled circles). The extent of the concentration dependent inhibition of IKD by TEA was estimated as $\mathrm{IKD}_{\mathrm{TEA}} / \mathrm{IKD}_{\mathrm{CTL}}$ (where $\mathrm{IKD}_{\mathrm{CTL}}$ indicates the values measured in the absence of TEA).

To evaluate the effect of TEA on the single components, IKV was isolated by adding external $0.2 \mathrm{mM} \mathrm{Cd}^{2+}$, and the blocking effect of the same concentrations of TEA was similarly computed $\left(\mathrm{IKV}_{\mathrm{TEA}} / \mathrm{IKV}_{\mathrm{CTL}}\right.$, open circles in Figure 2F; $n=4-7$ for each TEA concentration): the effect of TEA on IKV appears to be irrelevant for concentrations $<5 \mathrm{mM}$.

In these experiments, and in agreement with previous observations on higher numbers of hair cells, IKV accounted for $40 \%$ of the total compound IKD ( $39.9 \pm 3.2 \%$ in 31 cells).

Given the insensitivity of IKV to TEA concentrations $<5 \mathrm{mM}$, inhibition of IKCa by TEA was evaluated as: $\left(\mathrm{IKD}_{\mathrm{TEA}}-0.40 \cdot \mathrm{IKD}_{\mathrm{CTL}}\right) /\left(0.60 \cdot \mathrm{IKD}_{\mathrm{CTL}}\right)$ (triangles; same cell sample as for filled circles). The dose-response curves best fitting the data had the following parameters (see Eqn.1 in "Methods" Section): estimated affinity $K_{i}=3.1 \mathrm{mM}$, maximum block $M=83 \%$ and Hill's coefficient $h=0.43$ 


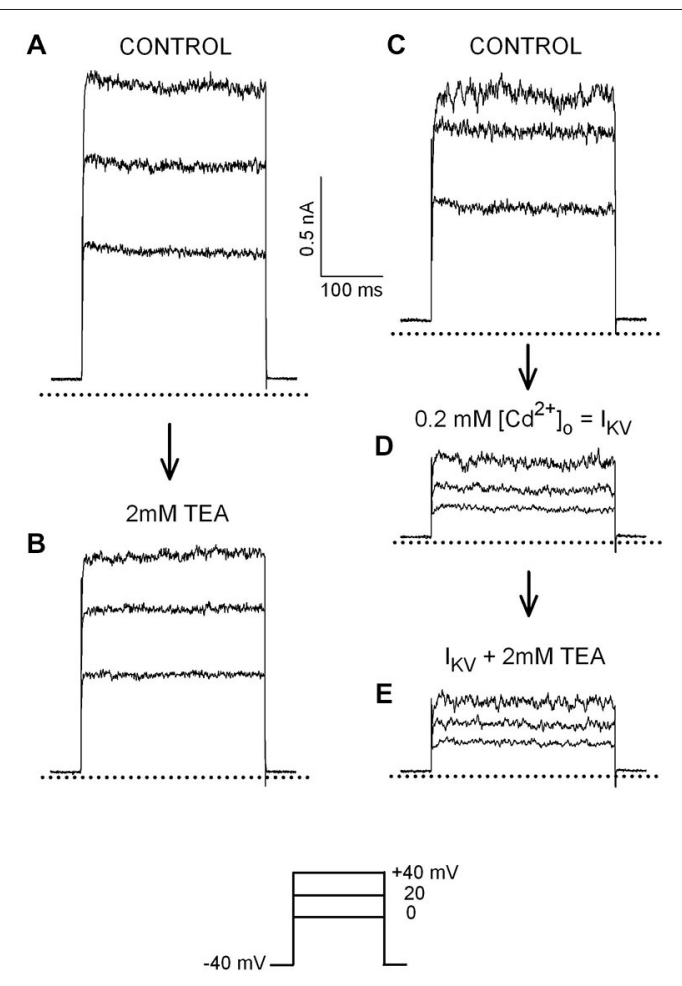

FIGURE 2 | Differential TEA blockade of the hair cell potassium currents. (A,B) The effect of external $2 \mathrm{mM}$ TEA on the delayed potassium current, IKD, evoked by voltage steps in the $0 /+40 \mathrm{mV}$ range, from $-40 \mathrm{mV}$ holding potential, in a representative frog hair cell. (C-E) Isolation of IKV: after blockade of the calcium inflow with $0.2 \mathrm{mM}$ cadmium (D) $2 \mathrm{mM}$ TEA does not affect the calcium-independent IKV (E), evoked by the same protocol. Dotted lines indicate zero current level. (F) Concentration-inhibition curves: IKD peak amplitude was measured in step tests at $+40 \mathrm{mV}$, in control saline and after fast TEA application; TEA inhibition was evaluated as IKD TEA $/ \mathrm{KL}_{\text {CTL }}$; data from 5-8 records in different cells were averaged for each TEA concentration (filled circles). IKV was isolated in the presence of

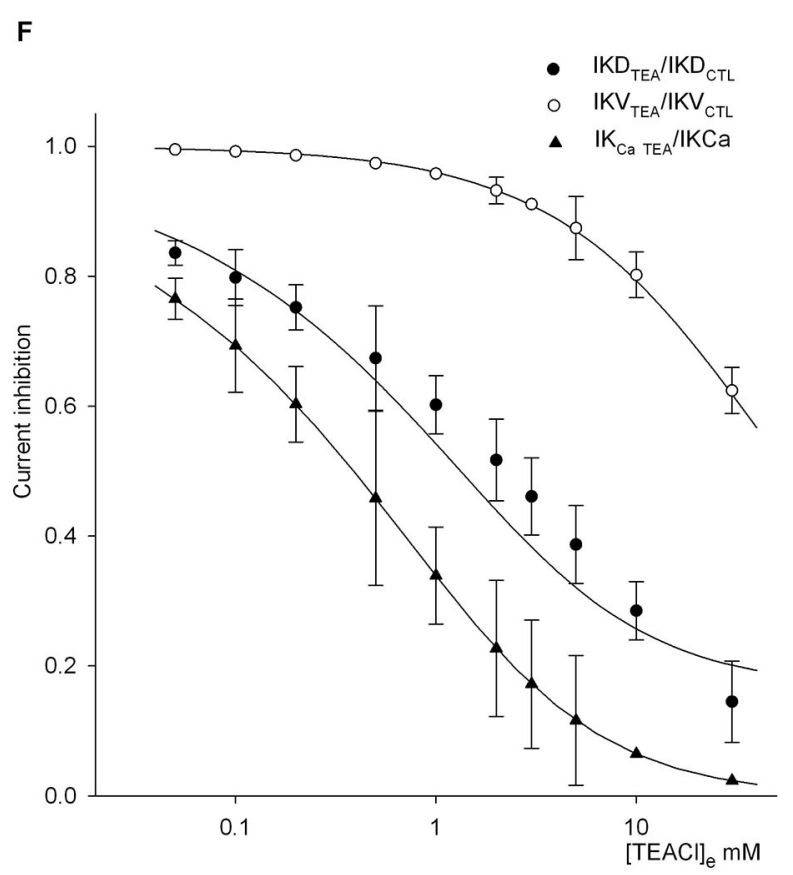

external $0.2 \mathrm{mM} \mathrm{Cd}{ }^{2+}$; TEA was then applied at different concentrations and its blocking effect was evaluated as $\mathrm{IKV}_{\mathrm{TEA}} / \mathrm{IKV} \mathrm{V}_{\mathrm{CTL}}$ (open circles; $n=4-7$ for each TEA concentration). IKCa amplitude was indirectly estimated in each IKD tracing of the figure (filled circles) by considering that IKV represents the $39.9 \pm 3.3 \%$ of the whole compound IKD $(n=31)$ and that IKV is unaffected by TEA at concentrations lower than $5 \mathrm{mM}$. Inhibition was thus estimated as: (IKD $\left.\mathrm{KEA}_{\mathrm{TEA}}-0.40 \cdot \mathrm{IKD}_{\mathrm{CTL}}\right) /\left(0.60 \cdot \mathrm{IKD}_{\mathrm{CTL}}\right)$ (triangles). The continuous lines were fitted to the data as described in the text. Note that the apparent IC50 is $19 \mathrm{mM}$ for IKV and $0.28 \mathrm{mM}$ for IKCa. Holding potential was $-40 \mathrm{mV}$ throughout. Bars indicate the SE of the mean value of the current peak amplitude. for the IKD data (apparent IC50 $=0.71 \mathrm{mM}$ ); $K_{i}=47 \mathrm{mM}$, $M=79 \%$ and $h=0.77$ for IKV (apparent IC50 = $19 \mathrm{mM}$ ) and $K_{i}=1.8 \mathrm{mM}, M=100 \%$ and $h=0.4$ for $\mathrm{IKCa}$ (apparent IC50 $=0.28 \mathrm{mM}$ ). In this analysis, IKCa accounted for $63.1 \%$ and IKV for $36.9 \%$ of the whole experimental IKD, respectively. The pooled data are consistent with a halfblocking concentration for IKCa nearly 50-fold lower than for IKV. High affinity for TEA actually is characteristic of largeconductance $\mathrm{Ca}^{2+}$-activated $\mathrm{K}^{+}$channels (Yellen, 1984), while a low affinity for TEA may indicate a purely voltage-gated $\mathrm{K}^{+}$ current, IKV.

In previous experiments we showed that IKD and IKCa currents exhibit similar activation time constant at any given potential (Martini et al., 2009, 2011), suggesting that IKCa and IKV channels open with similar kinetics during the depolarizing steps. Consistently, the time constant of the mono-exponential rising phase of IKD and IKV, calculated in the present experiments (five cells at $+40 \mathrm{mV}$ ), yielded similar values: $1.08 \pm 0.09$ and $0.99 \pm 0.03 \mathrm{~ms}$, respectively. These figures are virtually identical to the values obtained for IKD in the presence of $2 \mathrm{mM} \mathrm{TEA}(1.04 \pm 0.04 \mathrm{~ms}$ at
+40 $\mathrm{mV} ; n=5)$. Therefore, the kinetics of both components of IKD were unaffected by the drug, in spite of its effect on IKD size.

The data above on TEA effect have been obtained by stepping membrane potential from the $-40 \mathrm{mV}$ holding potential to $+40 \mathrm{mV}$; it was important to verify whether the drug was equally effective at any voltage. As previously reported (Martini et al., 2009), IKD machinery displays a voltage-dependent mechanism of partial steady-state inactivation. Inactivation is fully developed at $-40 \mathrm{mV}$; it is completely removed (slowly) at $-100 \mathrm{mV}$; this results in an increase of the evoked currents by a factor ranging 1.4-2, from the normal resting potential $(-70 \mathrm{mV})$ to $-100 \mathrm{mV}$. The coefficient of inactivation removal (ratio of IKD amplitude evoked from -100 or $-40 \mathrm{mV}$ holding potentials) was $1.63 \pm 0.09$ in control and $1.85 \pm$ 0.18 after exposure to $1 \mathrm{mM}$ TEA $(n=5$; difference not statistically significant in paired Student's $t$-test). This indicates that inhibition of IKD by TEA is independent of the inactivation machinery of this conductance. We next verified whether TEA block is also independent of the momentary membrane potential. 


\section{TEA Effect During Sinusoidal Voltage Shifts}

The effects of TEA were examined under conditions which more closely mimic, in the isolated hair cell, its physiological dynamic behavior during activity in the intact labyrinth, and in particular during mechanical stimulation. The membrane potential of the hair cell presumably fluctuates from an intermediate, "unstimulated" and partly depolarized level, close to $-40 \mathrm{mV}$ (with the cilia at an intermediate position and a fraction of the receptor transduction channels open), down to some $-70 \mathrm{mV}$ (all channels closed by the inhibitory deflection of the cupula) and up toward $0 \mathrm{mV}$, the upper limit set by the natural equilibrium potential of the transduction current (when additional transduction channels are open during the excitatory movements of the cupula). The receptor potential time course was therefore mimicked by driving the hair cell membrane potential along a sinusoidal waveform between -70 and $-10 \mathrm{mV}$ at $0.1 \mathrm{~Hz}$. Figure $\mathbf{3 A}$ illustrates representative current tracings evoked in the same cell in control saline and in the presence of either 2 or $3 \mathrm{mM}$ external TEA. The "difference current" between the tracings in the presence or absence of TEA depicts the time course of the outward current fraction actually blocked by each TEA concentration at any voltage level (which we conventionally named $I_{\text {TEA }}$ ). The mean $I_{\text {TEA }}$ waveforms (currently suppressed by $0.1-5 \mathrm{mM}$ TEA) are illustrated in Figure $3 \mathbf{B}$, while the mean inhibitory effects of the same TEA concentrations are reported in Figure 3C. The latter data points are fitted using Eqn. 2 ("Methods" Section), with $K_{i}=3.25 \mathrm{mM}$, $h=0.84$, and apparent IC50 $=2.5 \mathrm{mM}$, vs. $1.8 \mathrm{mM}$, the value reported above for TEA-mediated IKCa inhibition in voltage step experiments.

A full dynamic conductance-voltage relation was derived from these data by fitting the average current response to the sinusoidal voltage command. The data are illustrated in Figure 4A.

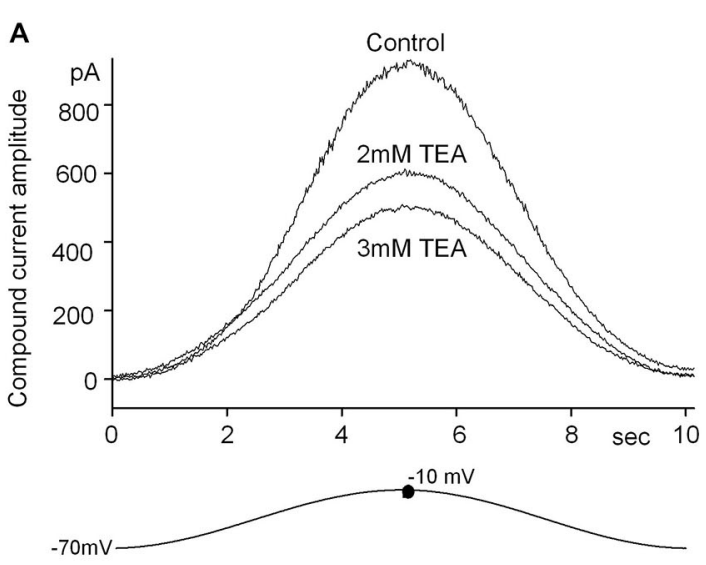

C

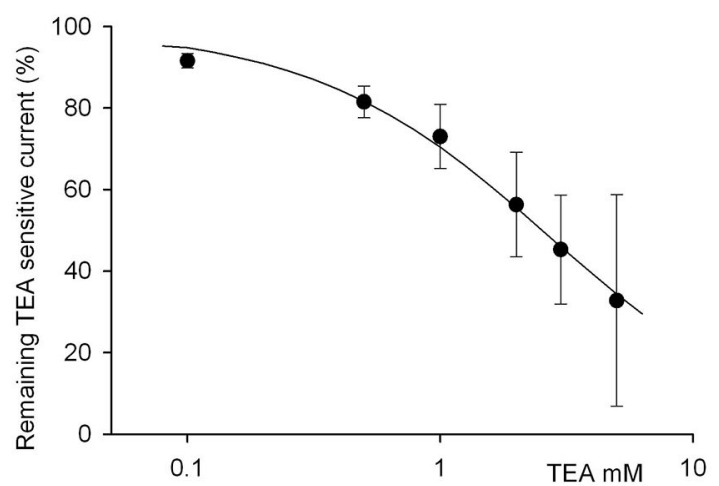

FIGURE 3 | Dissection of the current components suppressed by TEA. (A) Current tracings recorded during a single cycle of $0.1 \mathrm{~Hz}$ sinusoidal stimulation $(-70 /-10 \mathrm{mV}$ range; the precise $-10 \mathrm{mV}$ level is indicated by the dot) in an isolated hair cell before and after fast perfusion with 2 or 3 mM TEA. (B) The difference current before and after TEA application isolates the time course of the IKD current fraction suppressed by the blocker. Mean tracings of the IKD canceled by various TEA concentrations are illustrated ( $n=7-10$ for each mean recording). (C) Remaining current amplitude, normalized, after TEA application at the concentrations shown in (B). Data points are fitted by the equation indicated in the

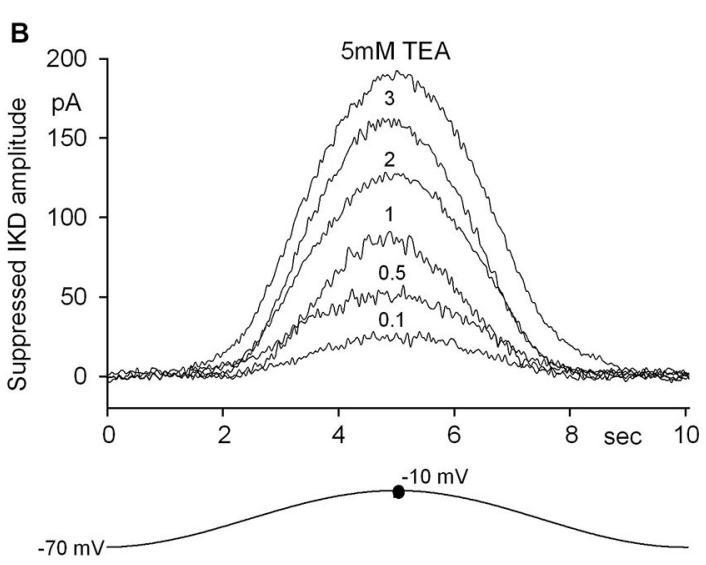

D

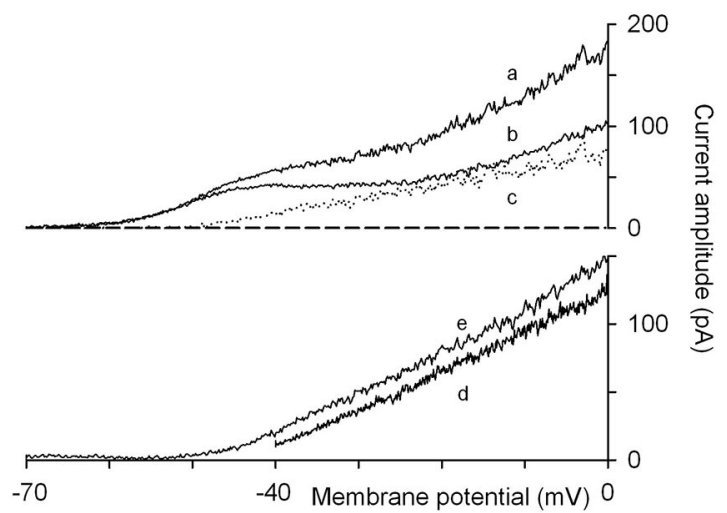

text to describe the TEA inhibition, with $K_{i}=3.25 \mathrm{mM}, h=0.84$ and an apparent IC50 $=2.5 \mathrm{mM}$. (D) Tracings recorded in a single cell during ramp voltage commands of $1 \mathrm{~s}$ duration in the

$-70 / 0 \mathrm{mV}$ range before (a) and after (b) $2 \mathrm{mM}$ TEA application. The difference current (c) shows that this procedure cancels the evident contaminating currents (mainly IA, and ICa) concomitantly activated by the depolarization. Mean difference currents ( $n=4 ; 5 \mathrm{mM}$ TEA) evoked by voltage ramps to $0 \mathrm{mV}$ starting from a holding potential of either $-40 \mathrm{mV}$ (d) or $-70 \mathrm{mV}$ (e) indicate that the suppressed $\mathrm{K}^{+}$conductance is constant over the range tested. Dashed line indicates the 0 current level. 
The resulting equation, describing TEA-sensitive potassium conductances, was:

$$
g_{T E A}(V)=\frac{G_{T E A}}{1+\exp (-(V+23.0) / 10.3)}
$$

where $g_{T E A}=4.3 \mathrm{nS}$ in control conditions, and the full dynamic behavior in the presence of TEA is well described by the equation:

$$
\begin{aligned}
g_{\text {TEA }}(V,[T E A])= & \frac{G_{T E A}}{1+\exp (-(V+23.0) / 10.3)} \\
& \times\left(\frac{[T E A]}{[T E A]+K_{i}}\right)^{h}
\end{aligned}
$$

The waveforms in Figure $\mathbf{3 A}$ are apparently asymmetrical, when the current amplitudes during the excitatory or inhibitory acceleration phases (excitatory and inhibitory hemicycle) are compared; evaluation of the charge movements actually indicates that the total charge during the inhibitory phase is smaller than during the excitatory phase by $4-19 \%$, in the various runs. The difference current procedure, in principle, cancels any contaminating current component insensitive to TEA, as ICa and IA actually are. The effective cancellation of TEA-insensitive components was verified more directly in experiments in which currents were observed during $-70 / 0 \mathrm{mV}$ voltage ramps. Figure 3Dab shows current tracings evoked in the same cell from a $-70 \mathrm{mV}$ holding level, before and after $2 \mathrm{mM}$ TEA application: the profiles actually confirmed the presence of different current components (here the contribution of IA is evident, due to inactivation removal during the sojourn at $-70 \mathrm{mV}$ holding potential). However, the difference current, i.e., TEA-sensitive current, exhibited a clear-cut linear I-V relation above $-40 \mathrm{mV}$ (Figure 3Dc). The mean difference currents shown in Figure 3Dde (5 mM TEA) confirm that the contaminating components were mutually canceled by the subtraction procedure, when the ramp starting level was either -40 (d) or $-70 \mathrm{mV}$ (e). Moreover, their constant slopes indicate that the fraction of $\mathrm{K}^{+}$conductance blocked by TEA was voltage-independent, at least over the $-40 / 0 \mathrm{mV}$ range.

The asymmetry during the rising and falling phases persisted in the difference currents and might thus be related to the activation/deactivation kinetics of the underlying channels. In Figure $\mathbf{3 A}$ most of the asymmetry seems to occur in the portion of the curves corresponding to $V_{\mathrm{m}}<-40 \mathrm{mV}$, where $I_{\text {TEA }}$ is negligible. However, a slight asymmetry persisted when difference currents $\left(I_{\mathrm{TEA}}\right)$ obtained at various TEA concentrations were normalized and plotted vs. $V_{\mathrm{m}}$, to produce the plot of $g_{\mathrm{TEA}}$ vs. $V_{\mathrm{m}}$ illustrated in Figure $4 \mathrm{~A}$. The resulting curves superimposed very well, indicating that TEA did not alter their shapes and thus confirming the voltage-independence of current block by TEA, even in the presence of asymmetry; the latter merely produced a slight hysteresis (difference between rising and falling phases) that can be perceived in the conductance vs. $V_{\mathrm{m}}$ plot (Figure 4A).
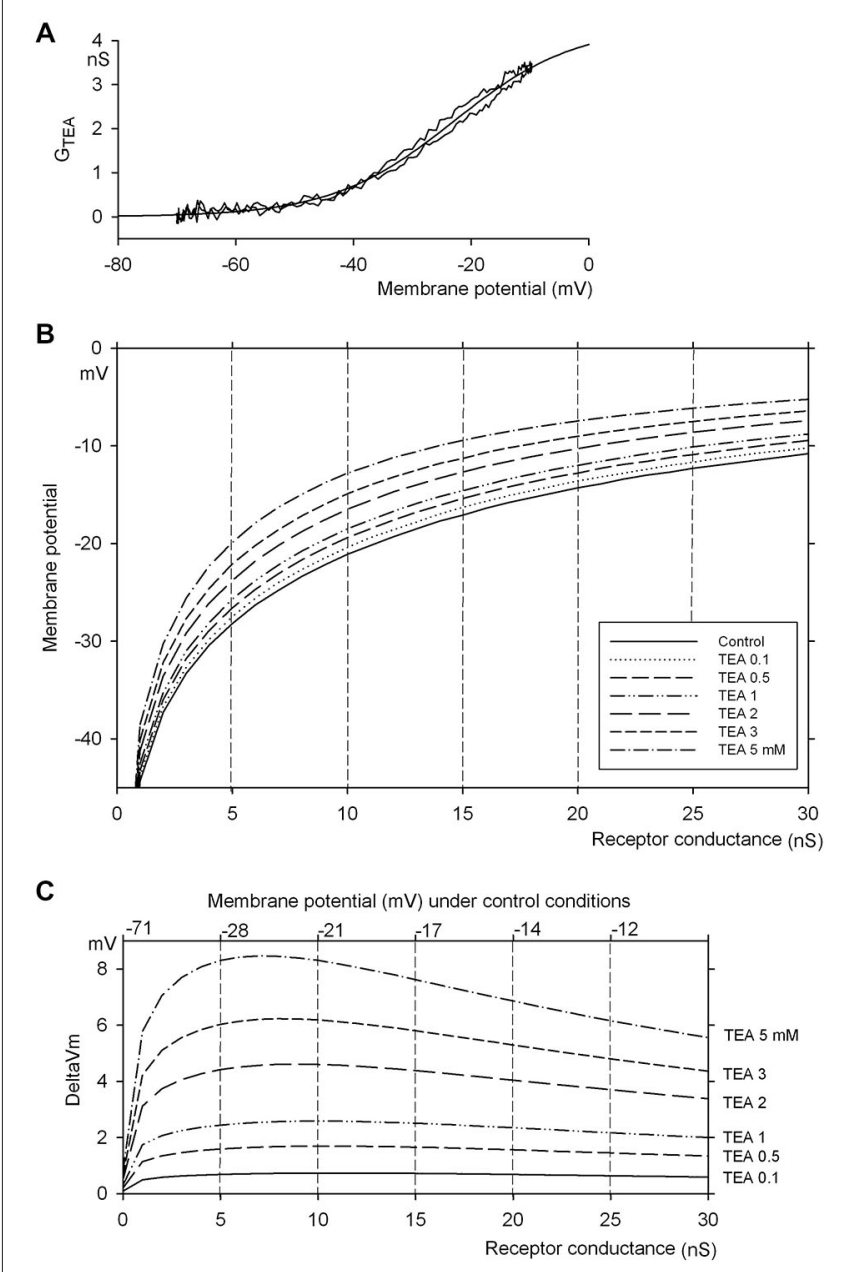

FIGURE 4 | Computation of the effect of TEA concentration on hair cell membrane potential. (A) Mean TEA sensitive conductance vs. membrane potential curve. The continuous line was obtained by averaging the traces in Figure $\mathbf{3 B}$, after scaling them up to the no-TEA condition, based on the inhibition curve in Figure $\mathbf{3 C}$. The dotted line is the Boltzmann equation best fitting the data (parameters reported in the text). (B) Hair cell membrane null potential, computed as a function of receptor conductance, based on the estimated TEA-sensitive voltage-dependent conductance (Panel (A)) and a lumped voltage-independent conductance $(0.76 \mathrm{nS}$, zero-current potential $-70 \mathrm{mV}$, see text), in control and in the presence of increasing concentrations of TEA. Notice that the curves become almost perfectly parallel for membrane potentials above $-30 \mathrm{mV}$. (C) shift of membrane potential produced by various concentrations of TEA (data from Panel $\mathbf{( B )}$ ), after subtracting the control curve). The numbers on top indicate the zero-current potential values corresponding to the transduction conductance in abscissa, in control conditions (no TEA). Notice that the shifts are almost voltage-independent in the range -30 to $-15 \mathrm{mV}$.

Thus, TEA constitutes a flexible, selective tool to produce the desired fractional block of IKCa under most experimental conditions.

\section{Electrical Effects of TEA Application}

Due to the interplay of receptor and voltage-dependent potassium currents, the observed fixed fractional block of voltage-dependent potassium current induces a relatively fixed 
shift of membrane potential, when the cell is depolarized in the range -30 to $-10 \mathrm{mV}$ (i.e., in presence of strong activation of the receptor current). At rest, the cell displays a baseline conductance of about $0.76 \mathrm{nS}$, with a zero-current potential of $-70 \mathrm{mV}$ : this compound voltage-independent conductance can be represented by

$$
C=\sum_{i=1}^{n} G_{i}
$$

and gives rise to a compound, "leak" current, given by

$$
I_{L K}=\sum_{i=1}^{n}\left(V-E_{i}\right) \cdot G_{i}=(V+70) \cdot C .
$$

In the presence of a receptor conductance $\left(g_{\mathrm{REC}}=\mathrm{G}_{0}\right.$, reversal potential $\approx 0 \mathrm{mV}$ ), the membrane potential (zero-current) can be computed as:

$$
V_{m}=\frac{E_{K} g_{K}+\sum_{i}^{n} E_{i} G_{i}}{g_{K}(V)+\sum_{i}^{n} G_{i}+g_{R E C}}=\frac{E_{K} g_{K}(V)-70 \cdot C}{g_{K}(V)+C+g_{R E C}},
$$

where $g_{K}(V)$ represents the voltage-dependent conductances (mostly potassium currents, as above mentioned). Increasing receptor currents produce increasing depolarizations. However, given the voltage dependence of $g_{K}(V)$, this will both enhance $g_{K}(V)$ activation and increase the driving force for $\mathrm{K}^{+}$ions, which will counteract the action of the receptor current. Thus, the amount of receptor current required to depolarize the cell by a fixed step increases with membrane depolarization; on the other hand, a partial block of $g_{K}(V)$ would cancel an amount of potassium current that similarly increases with membrane depolarization. This suggests that, independently of membrane potential-and the momentary level of activation of $g_{R E C}-\mathrm{a}$ fixed fractional block of $g_{K D}$ might produce a similarly sized depolarization, independent of the degree of activation of receptor current and the resulting membrane potential.

A basic numerical simulation, obtained by considering the description of $g_{K D}$ and "leak" current derived from these experiments (see above) actually confirms this prediction.

Figure 4B illustrates the membrane potential produced by a receptor conductance from 0 to $30 \mathrm{nS}$ (continuous line) and the effects of blocking 8, 18,27,44, 55, and $67 \%$ of $g_{K}(V)$, i.e., the block experimentally measured after applying $0.1,0.5$, $1,2,3,5 \mathrm{mM}$ TEA, respectively. The shifts in $V_{\mathrm{m}}$ produced by such block are illustrated in Figure $4 \mathrm{C}$ (the numbers at the top remap the receptor conductance in abscissa to the corresponding membrane potential in the absence of TEA): it can be observed that, for $\mathrm{g}_{R E C} \geq 4 \mathrm{nS}$ (i.e., a membrane potential $V_{\mathrm{m}} \geq-30 \mathrm{mV}$, as expected at the peak of rotational stimulation) an almost constant shift in membrane potential is produced by each fractional block $(0.69-0.73 \mathrm{mV}$ for $8 \%$ block, $1.6-1.7 \mathrm{mV}$ for $18 \%$, up to $7.2-8.5 \mathrm{mV}$ for $67 \%$ block), independent of the intensity of receptor current, over the range of membrane potential -30 to $-15 \mathrm{mV}$ (which constitutes a reasonable range for hair cell membrane potential at the peak of rotational stimulation).
This observation suggests that, even though the hair cell membrane potential (or the receptor current) cannot be measured in the intact preparation, application of a drug that can block a fixed fraction of $g_{K D}$ will produce a predictable shift in membrane potential, and the magnitude of such shift can be estimated based on the measurement of fractional inhibition of $g_{K D}$ in the isolated hair cell.

\section{mEPSP Discharge Properties in Control Units}

In experiments on isolated hair cells, the transmitter released by depolarization is wasted in the external saline. In the intact preparation, where the postsynaptic cell (that is the natural transmitter detector) is present, the native receptors disclose the characteristics of presynaptic quantal emission and of the postsynaptic response. A large amount of information can be extracted from a complex signal such as the afferent sensory discharge. Some parameters are presented in Table 1, as evaluated at rest or during $0.1 \mathrm{~Hz}$ rotatory stimulation at $12.5^{\circ} / \mathrm{s}^{2}$. An example of the tracings and analyses from which these data are derived is shown in Figure 5.

In these experiments a single stimulation pattern was tested; the following points of physiological interest can be stressed: (1) the cytoneural junction sustains a high mEPSP discharge level at rest; (2) the increment in quantal discharge rate during the excitatory hemicycle, after correction for the underlying Spontaneous activity (SA), was relatively scarce (a mean of $361 \pm 48$ quanta in a $5 \mathrm{~s}$ period-in the present example of $0.1 \mathrm{~Hz}$ rotatory stimulation at $12.5^{\circ} / \mathrm{s}^{2}$ ). However, if mEPSP discharge at rest brings the postjunctional membrane potential close to the spike-firing threshold, then even such a modest extra quantal release might be instrumental in determining the final sensory response that reaches the CNS (i.e., spike firing); (3) during the inhibitory hemicycle the frequency reaches a minimum that is clearly lower than the mean SA $(136 \pm 15$ vs. $209 \pm 21$ quanta/s; statistically different, $P<0.001$, paired $t$-test; $n=28$ ); however the peak of inhibition during the sinusoidal stimulation here applied is insufficient to completely turn off quantal release; (4) in the average, the evoked quantal release during the whole stimulation cycle is higher than at rest; actually, during the whole inhibitory hemicycle the average rate is not lower than during the initial $\mathrm{SA}$, indicating that during mechanical stimulation release is

TABLE 1 | mEPSP properties in control preparations at rest or during sinusoidal stimulation $\left(0.1 \mathrm{~Hz}, 12.5^{\circ} / \mathrm{s}^{2}\right)$.

Spontaneous activity (SA; mEPSPs/s)

$209 \pm 21$

Number of mEPSPs in the excitatory hemicycle

Number of mEPSPs in the excitatory hemicycle in excess of SA

Number of mEPSPs in the inhibitory hemicycle

Peak mEPSP frequency (mEPSPs/s; excitatory hemicycle)

Lowest mEPSP frequency (mEPSPs/s; inhibitory hemicycle)

mEPSP Peak Size during spontaneous activity ( $\mathrm{mV} ; n=7,856)$

mEPSP Peak Size in the excitatory hemicycle ( $\mathrm{mV} ; n=17,509)$

mEPSP Peak Size in the inhibitory hemicycle ( $\mathrm{mV} ; n=11,999)$

$1409 \pm 12$

$361 \pm 48$

$1048 \pm 99$

$315 \pm 23$

$136 \pm 15$

$0.65 \pm 0.005$

$0.66 \pm 0.003$

$0.60 \pm 0.003$ 
A

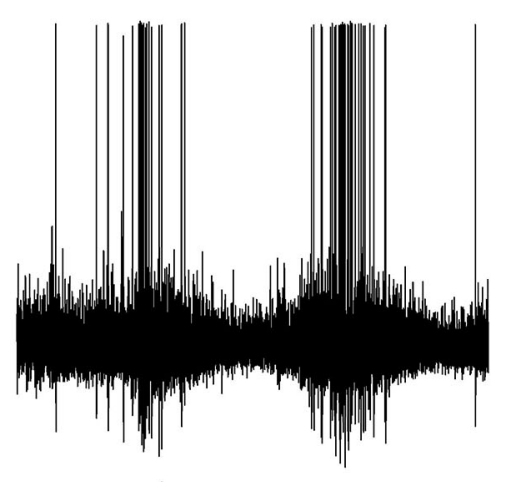

$\frac{10 \mathrm{mV}}{5 \mathrm{~s}}$

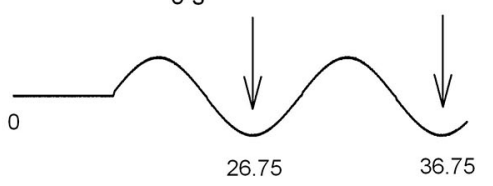

B

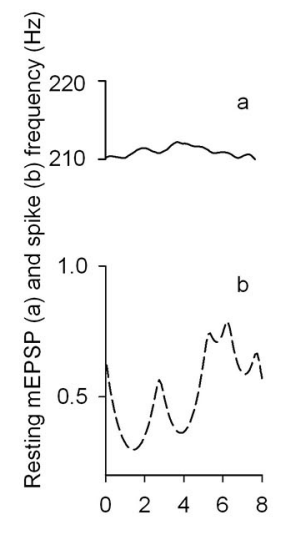

Time (s)
C
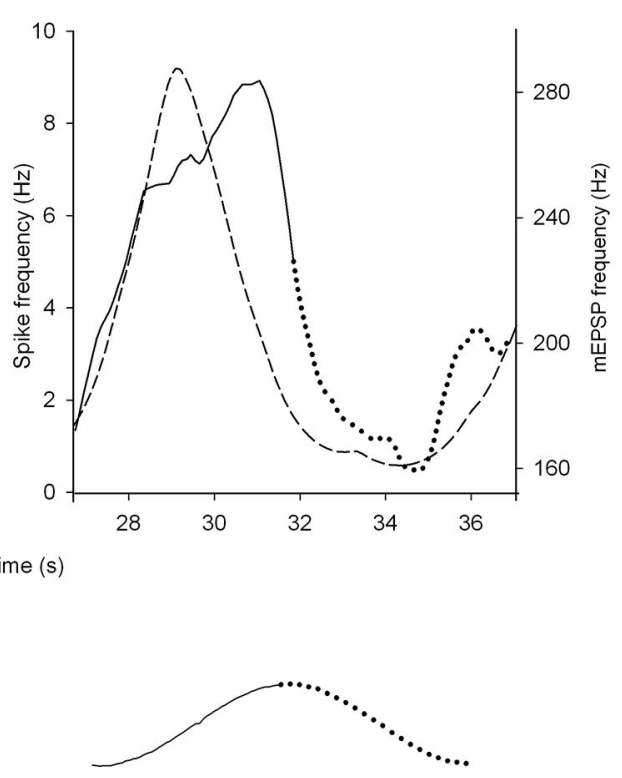

FIGURE 5 | Analysis of quantal emission and spike discharge at rest and during rotatory stimulation. (A) Intracellular recordings from an axon during a rest period followed by rotatory stimulation at $0.1 \mathrm{~Hz}$, $12.5 \% \mathrm{~s}^{2}$. Action potentials are truncated. The lower trace illustrates turn-table velocity (same time scale). The first complete cycle used in the analyses is marked by arrows in the velocity diagram of the turn-table rotation. Notice that synaptic activity anticipates turn-table velocity, but lags behind turn-table acceleration. (B) mEPSP (top) and spike (bottom) rates during the initial resting recording. (C) MEPSP (continuous-dotted line) and spike (dashed line) rates during a full cycle of rotation, as indicated by the bottom trace and the arrows in the bottom trace of Panel (A). The continuous line section, for mEPSP rate as well as turntable velocity, indicates the excitatory hemicycle, defined as the portion during which turntable acceleration is $\geq 0$; conversely, the dotted section indicates the inhibitory hemicycle. Notice that mEPSP rate anticipates turntable velocity by about $80^{\circ}$ (i.e., it is almost in phase with turntable acceleration); spike rate, conversely appears to anticipate some more degrees, moving in phase with turntable acceleration. modulated about a higher level than at rest (see "Discussion" Section).

\section{Effect of TEA on mEPSP Discharge}

We have shown that TEA treatment results in a robust decrease of the potassium current amplitude, which produces a decrease in the repolarizing capability of the hair cell, increased calcium influx and activation of the cytoneural junction. We therefore examined quantitatively the correlation between TEA concentration and mEPSP emission. The relevant parameters are summarized in Table 2, as an illustration of the effects of $1 \mathrm{mM}$ TEA on the native quantal discharge.

Additional results concerning TEA application in the 0.1-3 mM concentration range are summarized in Figures 6A,B; for clarity, only quantal emission rates are considered, focusing on their variation rather than on absolute values. In particular, two distinct measurements are presented: the variations in number of mEPSP during one-excitatory or inhibitory-hemicycle and the variations in maximum and minimum mEPSP frequencies during the stimulation cycles. The analysis was restricted to the 0.1-3 mM TEA concentration, because TEA obviously acts on the postjunctional membrane as well, and above $3 \mathrm{mM}$ it produces spontaneous repetitive activity in the nerve fibers; this effect becomes so relevant that a too large fraction of the record has to be eliminated by the spike deletion procedure, and the resulting measurements of mEPSP rate become unreliable; spiking rate itself becomes little informative, under these conditions.

The increase in mEPSP numbers vs. control, during the excitatory hemicycle, linearly paralleled TEA concentration up to $2 \mathrm{mM}$ TEA (Figure 6A; filled circles-correlation coefficient $r=0.99, P<0.01)$. The increase was statistically significant $(P<0.05$ in paired $t$-test $)$ at all TEA concentrations $(n=5-6$ for each data point). In the same cells, mEPSP numbers during the inhibitory hemicycle (Figure 6A, triangles) also exhibited an increase at all TEA concentrations $(P<0.05$, paired $t$-test), but the concentration dependence could not be consistently evaluated (regression through data points was not statistically significant). It should be observed that our analysis above indicates that below $-40 \mathrm{mV}$ (i.e., during the inhibitory cycle) the IKD rapidly declines and, consequently, the shift in membrane potential produced by TEA similarly declines (see Figure 4C). The same patterns-namely, a significant concentration-dependent increase during the excitatory hemicycle and a mild decrease with little/no concentration dependence during the inhibitory hemicycle-were observed after normalizing (i.e., by considering the percentage increases in mEPSPs numbers). 
TABLE 2 | Effect of $1 \mathrm{mM}$ TEA on some mEPSP discharge properties, at rest or during sinusoidal stimulation $\left(0.1 \mathrm{~Hz}, 12.5^{\circ} / \mathrm{s}^{2}\right)$.

\begin{tabular}{|c|c|c|c|}
\hline & Control & 1 mM TEA & Difference \\
\hline Spontaneous activity (SA) mEPSPs/s & $167 \pm 41$ & $234 \pm 48^{*}$ & $66 \pm 13$ \\
\hline Number of mEPSPs in the excitatory hemicycle & $1215 \pm 256$ & $1607 \pm 312^{*}$ & $392 \pm 130$ \\
\hline Peak mEPSP frequency (excitatory cycle) & $256 \pm 42$ & $401 \pm 40^{*}$ & $145 \pm 47$ \\
\hline Lowest mEPSP frequency (inhibitory hemicycle) & $87 \pm 17$ & $156 \pm 36$ & $69 \pm 25$ \\
\hline mEPSP Peak Size during SA (mV; $n=6,135$ vs.1,218) & $0.64 \pm 0.005$ & $0.63 \pm 0.009$ & \\
\hline
\end{tabular}

*Statistically different in paired $t$-test $(P<0.05) ; n=5$.

As it occurred in control preparations, the minimum mEPSP frequency during the inhibitory cycle was lower than SA (Table 2), i.e., a fraction of the spontaneous discharge was suppressed during the maximal inhibitory phase of the cycle.

The variations produced by the various TEA concentrations in peak and minimum mEPSP frequency vs. control are shown in Figure 6B (same cells as in A). For peak values the pattern was similar to that described for the whole hemicycle numbers: namely an apparent linear increase with increased TEA concentration up to $2 \mathrm{mM}(r=0.99, P<0.01)$, and a deflection from linearity at $3 \mathrm{mM}$ TEA. The minimum rates were apparently independent of TEA concentration (again consistent with the idea that at the moment of maximal inhibition, the IKD are shut and little effect is to be expected from TEA).

As shown for the 1-mM example (Table 2), the mEPSP peak size was not modified by the presence of TEA, either during SA or during the hemicycles of sinusoidal stimulation, even in the presence of relatively high TEA concentration. Typically, the mean spontaneous mEPSP peak size in five units, before and after $3 \mathrm{mM}$ TEA application, were $0.68 \pm 0.005$ $(n=8,422)$ vs. $0.75 \pm 0.005 \mathrm{mV}(n=9,732)$, respectively. This difference actually is significant $(P<0.05)$; however, its magnitude is quite small, and it might be fully accounted for by small changes in postjunctional conductances, brought about by TEA, which may affect the response of the post-junctional membrane. Altogether these data indicate that possible effects of TEA on the size of the elementary quantum of transmitter, or on the sensitivity of the postsynaptic transmitter receptor, are not relevant.

\section{A Quantitative Correlation Between IKD Blockade and mEPSP Discharge?}

Figure 3B shows the effect of TEA in suppressing a fraction of the outward potassium current, which has been quantitatively evaluated for each concentration tested. These effects were due to the block of variable amounts of the natural potassium conductance, activated by cell depolarization. The fractional block was voltage-independent in the -70 to $0 \mathrm{mV}$ range

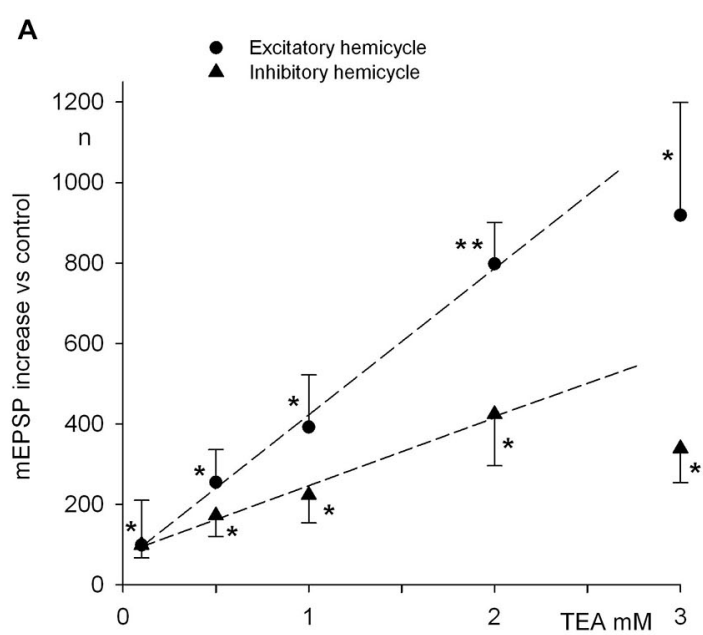

FIGURE 6 | mEPSP emission as a function of the applied TEA concentration. (A) Plot of the increase of mEPSP numbers vs. control as a function of TEA concentration, during the whole excitatory (closed circles) or inhibitory (triangles) hemicycles. Mean data from 5-6 cells for each TEA concentration tested. TEA effect was statistically significant in paired comparisons at all TEA concentrations $\left({ }^{\star} P<0.05\right.$; ${ }^{\star \star} P<0.01$; paired $t$-test).

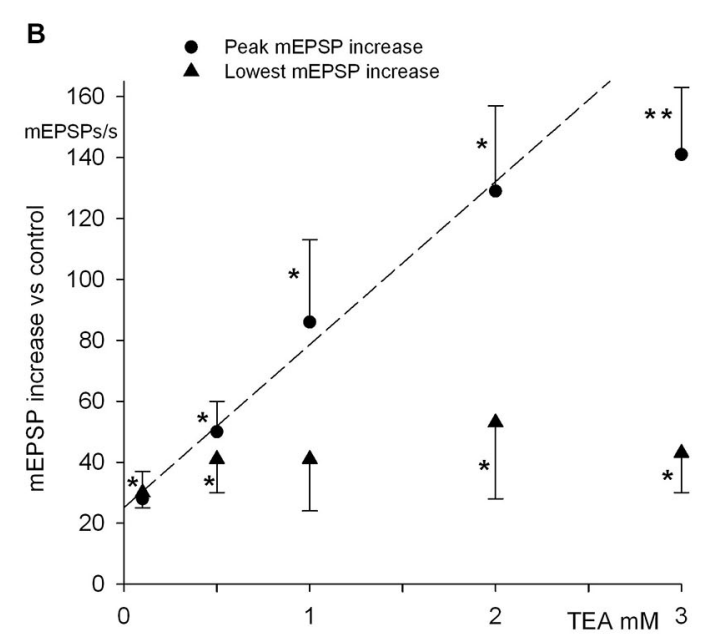

The straight lines indicate the best linear fit to data for $0.1-2$ mM TEA ( $r=0.99$, $P<0.01$ ). (B) Variations of the peak (closed circles) and minimum (triangles) mEPSP frequency vs. control values during $0.1 \mathrm{~Hz}$ sinusoidal cycles, plotted against TEA concentration (same units as in Panel (A)). The straight line was fitted as in Panel (A), with the same $r$ and $P$ values. TEA effect statistically significant where indicated (as in Panel (A)). 
TABLE 3 | Mean gK(V) inhibition, expected shift of hair cell membrane potential and net increase in peak mEPSP frequency during stimulation, as functions of external TEA concentration.

\begin{tabular}{|c|c|c|c|}
\hline TEA concentration ( $\mathrm{mM}$ ) & gK(V) inhibition (\%) & Membrane potential shift $(\mathrm{mV})^{*}$ & mEPSP peak frequency increase $(\mathrm{Hz})$ \\
\hline 0.1 & 8 & $+0.66(0.59-0.72)$ & $28 \pm 9$ \\
\hline 0.5 & 18 & +1.50 (1.35-1.65) & $50.4 \pm 19$ \\
\hline 1 & 27 & $+2.25(2.0-2.5)$ & $86 \pm 27$ \\
\hline 2 & 44 & +3.90 (3.4-4.4) & $129 \pm 28$ \\
\hline 3 & 55 & $+5.1(4.4-5.8)$ & $141 \pm 55$ \\
\hline 5 & 67 & $+6.6(5.6-7.6)$ & $==$ \\
\hline
\end{tabular}

*In parentheses the minimum-maximum values over the range -30 to $-15 \mathrm{mV}$.

(Figure 3D); during the sinusoidal voltage shifts, it was best evaluated at $-10 \mathrm{mV}$, i.e., when the driving force for $\mathrm{K}$ currents is maximal.

As discussed above, a fixed fractional block of TEAsensitive, IKD is expected to produce a depolarizing shift whose magnitude depends on the underlying interplay of conductances and momentary membrane potential. However, if the cell is depolarized (in the range of $-30 \mathrm{mV}$ or higher), as it is supposed to be at the peak of the excitatory phase of a rotation, then a fixed fractional block produces an almost constant shift of membrane potential (Table 3 ).

The parameters of mEPSP emission are plotted in Figures $7 \mathbf{A}, \mathbf{B}$ against the membrane potential shifts produced by TEA. The variations in absolute numbers of mEPSPs during the excitatory/inhibitory hemicycles (panel A) and in peak mEPSP emission frequency (panel B), are linearly related to the estimated variations in membrane potential. Statistical analysis indicates that the linear fit is quite good for excitatory responses ( $r=0.99, P<0.01$ in A,B), but not for the number of mEPSP during the inhibitory hemicycle (triangles in panel A). The straight line in each panel thus represents a sort of calibration curve to transform delta- $V_{\mathrm{m}}$ into mEPSP discharge changes and vice-versa, within the range explored. Functionally, this implies that a shift of $1 \mathrm{mV}$ in membrane potential generates: (1) the extra emission of 30.3 quanta/s at the peak of excitation (Figure 7B), at membrane potentials presumably more positive than $-15 \mathrm{mV}$; (2) the discharge of 221 extra mEPSPs, when maintained during the whole $0.1 \mathrm{~Hz}$ hemicycle (Figure 7A), i.e., in a presumable membrane potential range -40 to $-10 \mathrm{mV}$. The linear relation with membrane potential holds for shifts in the range $0-7 \mathrm{mV}$ at least.

Although a change in receptor conductance, $g_{\mathrm{REC}}$, produces a shift of membrane potential that depends on the latter (and on the resulting driving force across the transduction channel), the local slope $\mathrm{d} V / \mathrm{d} g_{\text {REC }}$ allows us to estimate the extra emission of quanta elicited by a small change in receptor conductance: $1 \mathrm{nS}$ of extra $g_{\text {REC }}$ at $-30 \mathrm{mV}$ will increase $\mathrm{mEPSP}$ frequency by $40.8 / \mathrm{s}$, whereas a similar change in conductance at $-15 \mathrm{mV}$ will produce the emission of 7.4 more quanta/s (Figure 8).

\section{TEA Effect on Afferent Spike Discharge}

The main target of the present experiments was understanding the properties of quantal emission at the cytoneural junction and its relation with hair cell depolarization. The presence of spikes in the tracings was still compatible with a reliable estimate of the mEPSP emission (see above in "Materials and Methods" Section); nonetheless in some experiments spiking was blocked by tricaine application, and in others bias was possibly introduced by selecting the non excessively spiking units. Despite these limits, the extra spike discharge observed after TEA application deserves a functional consideration. Spontaneous spiking was in the range $1-3 / \mathrm{s}(n=15)$ and was scarcely affected by 0.1-2 mM TEA; only at $3 \mathrm{mM}$ TEA spikes numbers increased by a mean of $72 \%(P<0.05$, paired $t$-test; $n=6)$. Figure $7 \mathrm{C}$ indicates that the extra spike numbers during the excitatory hemicycle increased with increasing depolarization. However, the effect was not directly proportional to the membrane potential shift and only was significant above $+2 \mathrm{mV}$ : since spike firing is a thresholded process, this may well be due to the temporal summation of mEPSPs required to trigger a spike.

\section{Discussion}

We studied some basic features of early sensory processing in the frog semicircular canal, a preparation in which the isolated hair cells are accessible to the patch-clamp analysis, while the afferent information can be recorded in the intact labyrinth. Owing to the presence of the cupula, single hair cells cannot be accessed electrophysiologically in the intact preparation; thus, in defining the properties of transmitter release by the hair cell its membrane potential (and its fluctuations during mechanical stimulation) must be indirectly evaluated.

\section{The Problem of the Hair Cell Membrane Potential}

Data from the literature suggest that amphibian saccular hair cells in situ and in vivo should have a resting membrane potential around $-70 \mathrm{mV}$ (Bracho and Budelli, 1978) and that the receptor conductance can change the membrane potential by some $8 \mathrm{mV}$ in mechanically stimulated isolated saccular hair cells (Hudspeth and Corey, 1977); in type II hair cells, a model derived from available data suggested a membrane potential fluctuation, in response to maximal cilium deflection, from -70 to -40 or $-30 \mathrm{mV}$, depending on the expression of the various conductances (Soto et al., 2002); a depolarization up to $-19 \mathrm{mV}$ was measured in vestibular hair cells of the chick held at a resting potential of $-43 \mathrm{mV}$ (Ohmori, 1985). 


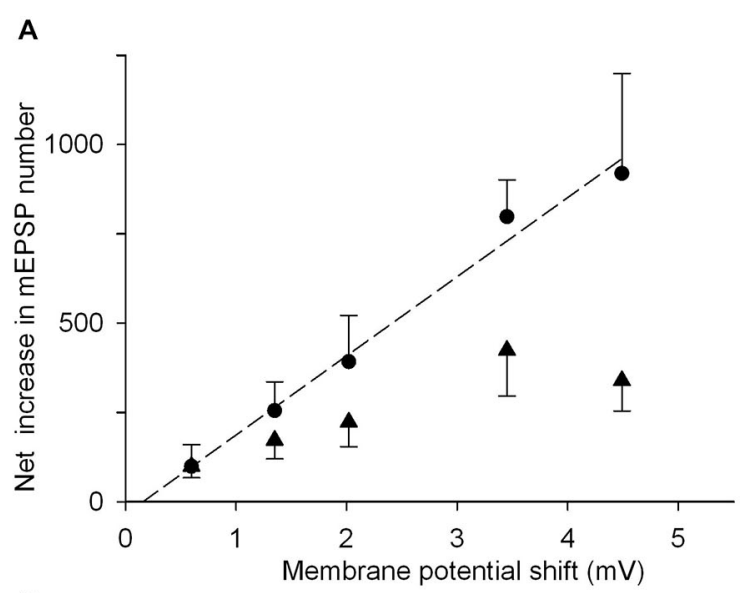

B

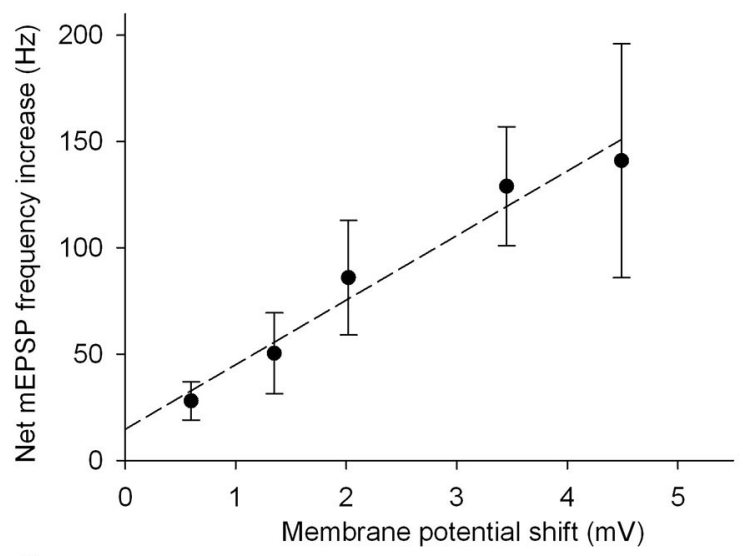

C

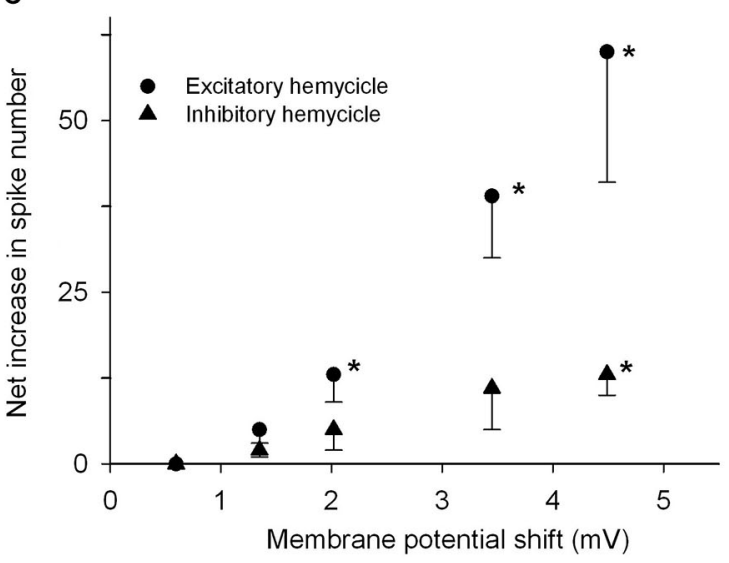

FIGURE 7 | Parameters of quantal release as a function of cell membrane depolarization. (A) Net increase, with respect to control, of mEPSP numbers discharged during the whole excitatory (filled circles) or inhibitory (triangles) hemicycles at $0.1 \mathrm{~Hz}$ sinusoidal rotation, plotted against the membrane potential shifts expected from TEA application. The straight line is the best linear fit to the data $(r=0.99, P<0.01)$, and indicates the sensitivity of the quantal release mechanism to membrane potential modifications (221 quanta/mV for the excitatory hemicycle). (B) Net mEPSP peak frequency increase vs. control as a function of membrane potential shifts. The straight line $(r=0.99, P<0.01)$ suggests that a mean of $30.3 / \mathrm{s}$ quanta are released per $\mathrm{mV}$ of membrane potential variation. (C) Afferent spike extra discharge (vs. control) as a function of membrane potential variation, during the whole

(Continued)

\section{FIGURE $7 \mid$ Continued}

excitatory or inhibitory hemicycle. Note the non-linear relationship and the statistical significance of the effect for membrane potential shifts $\geq 2 \mathrm{mV}$, in the excitatory hemicycle, ( ${ }^{*} P<0.05$ in paired $t$-test); for the inhibitory hemicycle, actually, the abscissa is meaningless, as the membrane potential shifts presumably are much smaller during the inhibitory phase (see the steep drop of delta- $V_{m}$ for small values of transduction conductance in Figure 4 C).

There are no means to measure hair cell membrane potential in the intact posterior canal; however, the above cited measurements, our estimate of resting potential in isolated hair cells from the posterior canal and reasonable physiological and functional considerations suggest that the membrane potential should physiologically oscillate between about $-70 \mathrm{mV}$ (resting potential in isolated hair cells, no receptor current) and a maximal depolarization in the -30 to $-20 \mathrm{mV}$ range (at the peak of mechanical stimulation).

\section{Potassium Conductances and the Effect of TEA}

Our previous work has indicated that most voltage-dependent current in canal hair cells is carried by potassium conductances (Martini et al., 2009). Although IA surely plays an important role in cochlear and vestibular hair cells subjected to rapid accelerations, in the face of slow mechanical rotations $(0.1 \mathrm{~Hz})$ and similarly slow membrane potential changes, its contribution is negligible, as it becomes inactivated as soon as it gets activated. Thus, voltage-dependent currents are dominated by the delayed potassium current, IKD, with its purely voltagedependent component (IKV) and its voltage- and calciumdependent component (IKCa).

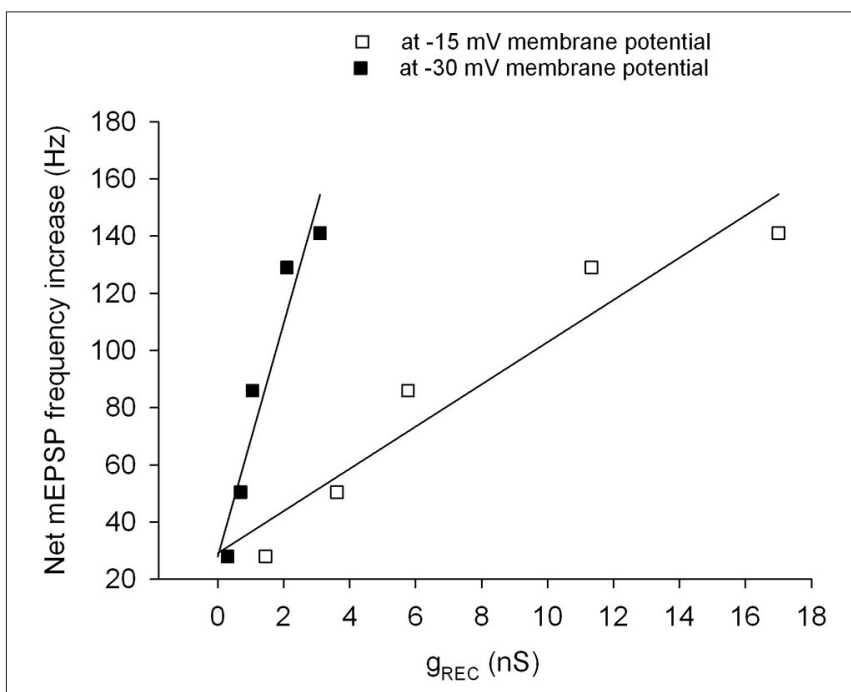

FIGURE 8 | Expected relationship between mEPSP rate and receptor conductance. Increase in peak mEPSP rate during rotational stimulation, produced by various concentrations of TEA, plotted vs. the receptor conductance that would produce the same shift of membrane potential, assuming a maximal depolarization either to $-30 \mathrm{mV}$ (filled symbols) or to $-15 \mathrm{mV}$ (open symbols). The regression lines would indicate a sensitivity for the quantal release machinery of $7-41$ quanta/s per nS of transduction conductance, depending on the maximal depolarization achieved. 
We show here that external TEA selectively blocks the IKCa of the isolated hair cell in a graded manner at concentrations lower than $5 \mathrm{mM}$, and that the extent of block by TEA is fixed in the membrane potential range -70 to $0 \mathrm{mV}$. We assumed that TEA application in the intact preparation might have the same effects as on the isolated hair cell, considering that the basolateral membrane of the hair cell is equally accessible to TEA.

During stimulation, increasing receptor currents produce increasing depolarizations. However, given the voltage dependence of $g_{K D}$, this enhances $g_{K D}$ activation and increases the potassium current driving force; both these events counteract the action of the receptor current. Thus, the amount of receptor current required to depolarize the cell by a fixed step increases with membrane depolarization; on the other hand, $g_{K D}$ also increases with membrane depolarization, and a fixed partial block cancels a similarly increasing amount of potassium current. Thus, independent of membrane potential-and the momentary level of activation of $g_{R E C}-\mathrm{a}$ fixed fractional block of $g_{K D}$ might produce a similarly sized depolarization, over a wide range of membrane potential.

In these experiments we measured the voltage-dependent potassium currents and estimated the size and reversal potential of a current through a lumped voltage-independent ("leak") conductance. The computation of the zero-current potentials produced by variable amounts of transduction conductance, $g_{\text {REC }}$, in the face of the measured currents, actually confirms the prediction that a fixed fractional block of voltagedependent conductances produces a membrane potential shift whose magnitude is essentially constant, independent of the prevailing membrane potential, at least within the range -30 to $-15 \mathrm{mV}$, a range which is supposed to comprise the actual peak depolarization during rotational stimulation of the intact labyrinth.

\section{Synaptic Transmission in Response to Hair Cell $V_{\mathrm{m}}$ Shift by TEA}

We therefore employed a series of concentrations of TEA as an instrument to produce reasonably predictable shifts of membrane potential at the peak of rotational stimulation, and measured several parameters of quantal emission and junctional activity at the cytoneural junction of the posterior canal in the isolated frog labyrinth.

A series of concentrations of TEA, corresponding to predicted shifts in membrane potential ranging from a fraction of $\mathrm{mV}$ to about $7 \mathrm{mV}$, were employed at rest and during rotational stimulation. A reasonably linear relationship was detected between the magnitude of membrane potential shifts and the net increase in relevant parameters of transmitter release: peak quantal emission, cumulative quantal release during an excitatory episode, spike firing activity. The procedure proved a useful tool to quantitatively evaluate the sensitivity of key aspects of the synaptic machinery to membrane potential.

These experiments lead to the following general considerations: (1) Resting hair cells display an intense SA, presumably due to $\mathrm{Ca}^{2+}$ inflow into the partially depolarized cell, since a significant fraction of the transduction channel population is open when the cilia are in their resting position; (2) The overall mean rate of quantal release during stimulation is higher than at rest-although each excitatory hemicycle is followed by an equally intense inhibitory hemicycle-as if mechanical stimulation per se were able to activate release (see below); (3) Quantal emission at the cytoneural junction during stimulation (at least in the $V_{\mathrm{m}}$ range -30 to $-15 \mathrm{mV}$ ) is linearly related to any small additive depolarization produced by the transduction current, over a relatively broad range of membrane potential; (4) A modest extra increase in mEPSP release is required to exceed action potential threshold and to activate the afferent fiber to transmit sensory information for central processing. This step is highly non-linear with respect to TEA-induced depolarization (or, presumably, the transduction current intensity) and is accompanied by large spatial-temporal summation in quantal emission; (5) For strong transduction current intensities the linear relationship between membrane potential and quantal release rate may be lost, because the depolarization may trespass the peak of the calcium I-V curve (Martini et al., 2000; Almanza et al., 2003; Bao et al., 2003); and (6) mEPSP peak amplitude is not affected in any consistent relevant manner by TEA, either at rest or during the excitatory/inhibitory hemicycles of rotatory stimulation.

The last-mentioned result appears to be in contrast with the data reported by Holt et al. (2006), who reported variable size and non-quantal behavior in the turtle posterior crista; however, in that preparation types I and II hair cells coexist and the complexity of intercellular contacts might favor the accumulation of potassium and glutamate and generate nonquantal activity. In the frog semicircular canals only type II hair cells with simple synaptic boutons are present and transmitter release displays a quantal behavior (Rossi et al., 1994). Entering further discussion of the mechanisms that might affect quantal size in the present experiments would be outside the target of this work.

\section{Estimating the Quantitative Relations Among Mechanical Stimulation, Hair Cell $V_{\mathrm{m}}$ Shift, Receptor Conductance and Transmitter Release}

Some numerical examples might help to better define the general behavior of an ideal hair cell at the frog semicircular canal, as derived from the present, limited, observations. It should be stressed, however, that each parameter considered is affected by the large intrinsic variability among cells, and that modest quantitative modifications of one or more variables can easily generate the broad spectrum of physiological properties of single units observed in vivo.

Spontaneous synaptic activity, in the absence of stimulation, is present when the ciliary apparatus is in intermediate position at rest, and the resulting relatively high spontaneous afferent activity allows the hair cell to respond to stimuli in both directions, by either increasing or decreasing transmitter release. SA may also increase the sensitivity of the whole system, because the postjunctional membrane is displayed toward to the spike encoder threshold and even a small increase in stimulus intensity 
may markedly affect the frequency of spike discharge. These properties are readily verified at labyrinthine hair cells, where mEPSP emission can be examined.

Although the variability of quantal release is quite marked among units (about $\pm 20 \%$ SE in the present control sample), the effects of mechanical stimulation and/or the application of drugs can be studied by focusing on the changes they produce in each cell; these changes are much more consistent and a tentative numerical description of the process can be attempted using the average values.

In our sample, the mean spontaneous quantal release at rest (cilia in resting position, partial depolarization) is about $210 \pm 21$ quanta/s; an average of $36 \pm 8$ quanta/s are added by stimulation (246/s $\pm 22 / \mathrm{s}$ average rate during the whole cycle), although the equivalent excitatory and inhibitory phases of stimulation should compensate each other. This might be due to some inactivation of $\mathrm{K}^{+}$conductances during the depolarizing phase (Martini et al., 2009) or to the slow kinetics of $\mathrm{Ca}^{2+}$ disposal: the dynamics of intracellular calcium ion levels are complex (see, e.g., Scullin and Partridge, 2010); passive diffusion and buffering by $\mathrm{Ca}^{2+}$-binding proteins, uptake into the ER by the endoplasmic reticulum $\mathrm{Ca}-\mathrm{ATPase}$ and extrusion across the cell membrane by the plasma membrane $\mathrm{Ca}^{2+}$-ATPase (neither $\mathrm{Na}$ :Ca nor $\mathrm{Na}: \mathrm{Ca}$, $\mathrm{K}$ exchanger operate in semicircular canal hair cells; Martini et al., 2002) contribute to restoring resting levels, while $\mathrm{Ca}^{2+}$ dependent $\mathrm{Ca}^{2+}$ release through ryanodine receptors and IP3induced release from the endoplasmic reticulum might produce more persistent increases in $\mathrm{Ca}^{2+}$ levels, and transmitter release, at hair cells (Lelli et al., 2003; Rossi et al., 2006). In particular the average rate rises to about $282 \pm 24$ quanta/s $(+73 \pm 10$ quanta/s vs. SA) during the excitatory hemicycle, and it attains $316 \pm 24$ quanta/s at the peak of the excitatory stimulation $(+106 \pm 10$ quanta/s vs. spontaneous release). Conversely, during the inhibitory hemicycle the average rate declines to the same level as during the SA $(210 \pm 21$ quanta/s $)$ and it falls to $136 / \mathrm{s}$ at the peak of inhibition ( $-74 / \mathrm{s}$ vs. spontaneous release).

One may try to evaluate the effect of closing the receptor channels by subtracting the average release rate during the whole stimulation from the momentary rate at the peak of inhibition (136-246 = -110 quanta/s); if this quantity is subtracted from the SA, a rate of some 100 quanta/s remains. This might suggest that the stimulus intensity here used was not sufficient to close all the channels; alternatively, the closure of receptor channels during the inhibitory cycle, even if it were complete, was only transient, and therefore possibly less effective (see also the above considerations about possible "residual" $\mathrm{Ca}^{2+}$ ).

\section{Quantitative Considerations on Sensory Input Convergence}

The extra release of about 360 quanta during the 5-s excitatory hemicycle (compared to the 1045 quanta that would have been released spontaneously during the same period) appears to be sufficient to generate the afferent information for central processing.

The gross organization of the posterior semicircular canal in the frog is constituted by about 4,000 hair cells in the sensory epithelium of the whole crista (data derived from Russo et al.,
2007), innervated by some 600 afferent fibers (Taglietti et al., 1973). To a first approximation, a single fiber should contact a mean of 6-7 hair cells. The ampullar nerve contains a fraction $(\approx 10 \%)$ of large myelinated fibers, larger than $8 \mu \mathrm{m}$, which most likely are the ones impaled by the microelectrode. As described in the bullfrog (Honrubia et al., 1989), in frog the thick afferent fibers turn toward the more central region of the crista and receive little convergence of afferent impulses (Taglietti et al., 1973). Thus, the sensory units considered here are comprised of few hair cells, arranged in parallel, with relatively homogeneous biophysical properties, as known from patch-clamp analysis. The functional variability observed in individual primary fibers is likely due to the innervation pattern and to the properties of the encoder system of each fiber, rather than to the transduction mechanism itself, as originally suggested by Precht et al. (1971). From our computations, each $\mathrm{nS}$ of transduction current should produce a shift in membrane potential of about $1.6 \mathrm{mV}$ (at $-30 \mathrm{mV}$ membrane potential) or $0.29 \mathrm{mV}$ (at $-15 \mathrm{mV}$ ), and consequently contribute about 7-41 quanta/s (at -15 or $-30 \mathrm{mV}$, respectively) to an afferent fiber, i.e., an additional release of 1-6 quanta/s per hair cell. This would correspond to the emission of about 55-300 quanta (8-45 per hair cell) during the 5-s excitatory hemicycle analyzed here.

\section{This Approach can only be Applied to Depolarized Hair Cells}

One may wonder why we did not simply examine the effects of TEA on quantal release in the resting preparation, rather than during mechanical stimulation. The resting hair cell presumably is sitting in a region below the threshold of TEA sensitive currents (Figures 3D, 4A) and where the shift of $V_{\mathrm{m}}$ produced by a given concentration of TEA is far from constant (Figure 4C). There, the effect of TEA on membrane potential is less predictable (see, in Figure 4, how the shift in membrane potential produced by TEA becomes highly voltage-dependent for membrane potentials more negative than $-30 \mathrm{mV}$ ), and its effects on quantal release cannot be related to a reliably estimated membrane potential shift (and to a corresponding change in receptor conductance). Actually, quantal release in the resting preparations was affected in a variable way by TEA (data for $1 \mathrm{mM}$ TEA in five units are reported in Table 2, but a dose effect curve was not even attempted in a larger sample).

In the region of potassium current activation, the null-point of the interaction between the receptor current and potassium currents (mostly IKD) determines the zero-current potential of the hair cell membrane and consequently the quantal emission at the cytoneural junction. Independent of the variability among single cells, a relevant control mechanism in each cell consists in the time- and voltage-dependent process of $g_{K D}$ inactivation, which can modify maximum amplitude of IKD by a factor up to 1.8 , if the cell is held at $-100 \mathrm{mV}$ instead of the typical $-40 \mathrm{mV}$ potential in the resting preparation, or 1.2 if it is held at $-70 \mathrm{mV}$. Independent of the steady-state inactivation mechanism, IKD is a quite strong current (several nA) and requires a similarly strong transduction current to be generated in order to have significant effects at the cytoneural junction. 
The range of possible transduction conductances considered in the present paper (up to $20 \mathrm{nS}$ ) exceeds the values measured in various hair cells or assumed in cell models (0.65-7.5 nS: Holton and Hudspeth, 1986; Soto et al., 2002; Zeddies and Siegel, 2004; Neiman et al., 2011).

Provided the I-V curve for IKD is not modified in shape but only scaled down by TEA, increased transduction conductance will shift the null-point towards more positive potentials (Figure 4). Hair cell synapses appear to operate with a linear $\mathrm{Ca}^{2}$ dependence of release, as shown in the frog papilla (Keen and Hudspeth, 2006), in mouse cochlea (Brandt et al., 2005; Johnson et al., 2005) and turtle papilla (Schnee et al., 2005) by using capacitance recordings. Since above a certain $V_{\mathrm{m}}$ calcium current stops increasing and rather decreases (the I-V for ICa displays a maximum between -25 and $-10 \mathrm{mV}$ ), our observations on quantal release suggest we are not pushing the membrane potential above the peak of Calcium current I-V peak. Receptor potentials, occasionally larger than $15 \mathrm{mV}$, were evoked in bull frog saccular hair cells by direct mechanical stimulation of their hair bundle in the excitatory direction. Similarly large transient depolarizations were recorded in vestibular hair cells of the chick, following mechanical stereociliary shift: their amplitude was $24 \mathrm{mV}$ at $-43 \mathrm{mV}$ holding potential and $30 \mathrm{mV}$ at $-70 \mathrm{mV}$ holding potential (Hudspeth and Corey, 1977; Ohmori, 1985). Under the rotatory stimulation used in the present experiments, the maximum calcium inflow occurs at about $-25 \mathrm{mV}$ (see Figure 8 in Rossi et al., 2010); since hair cells likely exhibit a resting potential of about $-45 \mathrm{mV}$, the voltage range over which calcium entry in expected to rise linearly and feed a linear increase in the quantal emission rate, is restricted to a $20 \mathrm{mV}$ range, included within the rising branch of the ICa I-V curve. Negative to $-45 \mathrm{mV}$, the calcium channels are progressively closed (the ICa activation curve starts at $-50 /-52 \mathrm{mV}$ ), and above $-25 \mathrm{mV}$ calcium inflow significantly decreases (Rossi et al., 2010), thereby shunting the effects of increased transduction current on transmitter release: possible further depolarization is not expected to produce additional quantal emission.

By applying TEA at high concentrations we should have changed the membrane potential, at the peak of excitation during

\section{References}

Almanza, A., Vega, R., and Soto, E. (2003). Calcium current in type I hair cells isolated from the semicircular canal crista ampullaris of the rat. Brain Res. 994, 175-180. doi: 10.1016/j.brainres.2003.09.033

Bao, H., Wong, W. H., Goldberg, J. M., and Eatock, R. A. (2003). Voltage-gated calcium channel currents in type I and type II hair cells isolated from the rat crista. J. Neurophysiol. 90, 155-164. doi: 10.1152/jn.00244.2003

Bracho, H., and Budelli, R. (1978). The generation of resting membrane potentials in an inner ear hair cell system. J. Physiol. 281, 455-465. doi: 10.1113/jphysiol. 1978.sp012432

Brandt, A., Khimich, D., and Moser, T. (2005). Few CaV1.3 channels regulate the exocytosis of a synaptic vesicle at the hair cell ribbon synapse. J. Neurosci. 25, 11577-11585. doi: 10.1523/jneurosci.3411-05.2005

Brichta, A. M., Aubert, A., Eatock, R. A., and Goldberg, J. M. (2002). Regional analysis of wholecurrents from hair cells of the turtle posterior crista. J. Neurophysiol. 88, 3259-3278. doi: 10.1152/jn.00770.2001 a rotational stimulus, by up to $7 \mathrm{mV}$; this would correspond to an extra transduction conductance slightly above $3 \mathrm{nS}$ (if the membrane potential were $-30 \mathrm{mV}$ ) or up to $17 \mathrm{nS}$ (for $-15 \mathrm{mV}$ membrane potential). We do not know whether such large receptor conductances can be generated in frog hair cells. The maximum transducer conductance estimated by Crawford et al. (1991) and Kros (1996) was around $13 \mathrm{nS}$; from our data and computations, a linear relation should hold between quantal emission and transducer conductance up to this value. Above this value, however, and above $-10 \mathrm{mV}$ in particular, calcium inflow, and quantal emission, may even decrease.

\section{Dynamic Changes During Rotational Stimulation}

A final consideration must be dedicated to a possible problem raised by mechanical stimulation. Quantal release as well as spike firing at the cytoneural junction displays marked hysteresis, i.e., an asymmetry between the rising and falling phases of mechanical stimulation (e.g., Rossi et al., 1989, 2010); similarly, the current profiles at the hair cell are sensitive to the previous history of membrane potential, because complex processes of time- and voltage-dependent inactivation, and recovery from inactivation, influence the availability of channels sustaining IA as well as IKD (Martini et al., 2009); this produces asymmetric current time-courses when the hair cell is driven along a sinusoidal voltage path. These observations have been confirmed in this study, and similar asymmetry is shown to affect the TEA-sensitive fraction of $\mathrm{K}$ currents, which is in agreement with previous observations about inactivation of delayed $\mathrm{K}^{+}$ currents (Martini et al., 2009); such asymmetry, however, is quantitatively limited (4-19\%) and does not interfere with the main aspect here studied, namely the properties of the hair cell and junctional transmission at the peak of excitatory stimulation (or during the whole excitatory hemicycle, so that possible asymmetries in rising and falling phases cancel each other out).

\section{Acknowledgments}

We thank Prof. Oscar Sacchi for his helpful comments on our manuscript.

Catacuzzeno, L., Fioretti, B., and Franciolini, F. (2003). Voltage-gated outward K currents in frog saccular hair cells. J. Neurophysiol. 90, 3688-3701. doi: 10. 1152/jn.00308.2003

Corey, D. P., and Hudspeth, A. J. (1979). Ionic basis of the receptor potential in a vertebrate hair cell. Nature 281, 675-677. doi: 10.1038/281675a0

Crawford, A. C., Evans, M. G., and Fettiplace, R. (1991). The actions of calcium and mechano-electrical transducer current of turtle hair cells. J. Physiol. 434, 369-398. doi: 10.1113/jphysiol.1991.sp018475

Fettiplace, R. (2009). Defining features of the hair cell mechanoelectrical transducer channel. Pflügers Arch. 458, 1115-1123. doi: 10.1007/s00424-0090683-X

Gillespie, P. G., and Müller, U. (2009). Mechanotransduction by hair cells: models molecules and mechanisms. Cell 139, 33-44. doi: 10.1016/j.cell.2009. 09.010

Goldberg, J. M. (1991). The vestibular end organs: morphological and physiological diversity of afferents. Curr. Opin. Neurobiol. 1, 229-235. doi: 10. 1016/0959-4388(91)90083-j 
Goldberg, J. M., and Brichta, A. M. (2002). Functional analysis of whole cell currents from hair cells of the turtle posterior crista. J. Neurophysiol. 88, 3279-3292. doi: 10.1152/jn.00771.2001

Holt, J. C., Xue, J.-T., Brichta, A. M., and Goldberg, J. M. (2006). Transmission between type II hair cells and bouton afferents in the turtle posterior crista. J. Neurophysiol. 95, 428-452. doi: 10.1152/jn.00447.2005

Holton, T., and Hudspeth, A. J. (1986). The transduction channel of hair cells from the bull-frog characterized by noise analysis. J. Physiol. 375, 195-227. doi: 10. 1113/jphysiol.1986.sp016113

Honrubia, V., Hoffman, L. F., Sitko, S., and Schwartz, I. R. (1989). Anatomical and physiological correlates in bullfrog vestibular nerve. J. Neurophysiol. 61, 688-701.

Housley, G. D., Norris, C. H., and Guth, P. S. (1989). Electrophysiological properties and morphology of hair cells isolated from the semicircular canal of the frog. Hear. Res. 38, 259-276. doi: 10.1016/0378-5955(89)90070-1

Hudspeth, A. J., and Corey, D. P. (1977). Sensitivity, polarity and conductance change in the response of vertebrate hair cells to controlled mechanical stimuli. Proc. Natl. Acad. Sci. U S A 74, 2407-2411. doi: 10.1073/pnas.74.6.2407

Johnson, S. L., Marcotti, W., and Kros, C. J. (2005). Increase in efficiency and reduction in $\mathrm{Ca}^{2+}$ dependence of exocytosis during development of mouse inner hair cells. J. Physiol. 563, 177-191. doi: 10.1113/jphysiol.2004.074740

Keen, E. C., and Hudspeth, A. J. (2006). Transfer characteristics of the hair cell's afferent synapse. Proc. Natl. Acad. Sci. U S A 103, 5537-5542. doi: 10.1073/pnas. 0601103103

Kim, K. X., and Fettiplace, R. (2013). Developmental changes in the cochlear hair cell mechanotransducer channel and their regulation by transmembrane channel-like proteins. J. Gen. Physiol. 141, 141-148. doi: 10.1085/jgp.201210913

Kros, C. J. (1996). "Physiology of mammalian cochlear hair cells," in The cochlea, eds P. Dallos, A. N. Popper, and R. R. Fay (New York: Springer), 318-385.

Lang, D. G., and Correia, M. J. (1989). Studies of solitary semicircular canal hair cells in the adult pigeon. II. Voltage-dependent ionic conductances. J. Neurophysiol. 62, 935-945.

Lelli, A., Perin, P., Martini, M., Ciubotaro, C. D., Prigioni, I., Valli, P., et al. (2003). Presynaptic calcium stores modulate afferent release in vestibular hair cells. J. Neurosci. 23, 6894-6903.

Martini, M., Canella, R., Fesce, R., and Rossi, M. L. (2009). Isolation and possible role of fast and slow potassium current components in hair cells dissociated from frog crista ampullaris. Pflügers Arch. 457, 1327-1342. doi: 10. 1007/s00424-008-0598-y

Martini, M., Canella, R., Fesce, R., and Rossi, M. L. (2013). The amplitude and inactivation properties of the delayed potassium currents are regulated by protein kinase activity in hair cells of the frog semicircular canals. PLoS One 8:e67784. doi: 10.1371/journal.pone.0067784

Martini, M., Canella, R., Prigioni, I., Russo, G., Tavazzani, E., Fesce, R., et al. (2011). Acute effects of gentamicin on the ionic currents of semicircular canal hair cells in the frog. Hear. Res. 282, 151-160. doi: 10.1016/j.heares.2011. 08.011

Martini, M., Rossi, M. L., Farinelli, F., Mammano, F., Mammano, F., and Rispoli, G. (2002). No evidence for calcium electrogenic exchanger in frog semicircular canal hair cells. Eur. J. Neurosci. 16, 1647-1653. doi: 10.1046/j.1460-9568.2002. 02234.x

Martini, M., Rossi, M. L., Rubbini, G., and Rispoli, G. (2000). Calcium currents in hair cells isolated from semicircular canals of the frog. Biophys. J. 78, 1240-1254. doi: 10.1016/s0006-3495(00)76681-1

Masetto, S., Russo, G., and Prigioni, I. (1994). Differential expression of potassium currents by hair cells in thin slices of frog crista ampullaris. J. Neurophysiol. 72, $443-455$.

Neiman, A. B., Dierkes, K., Lindner, B., Han, L., and Shilnikov, A. L. (2011). Spontaneous voltage oscillations and response dynamics of a Hodgkin-Huxley type model of sensory hair cells. J. Math. Neurosci. 1:11. doi: 10.1186/21908567-1-11

Ohmori, H. (1985). Mechano-electrical transduction currents in isolated vestibular hair cells of the chick. J. Physiol. 359, 189-217. doi: 10.1113/jphysiol.1985. sp015581
Pfanzelt, S., Rössert, C., Rohregger, M., Glasauer, S., Moore, L. E., and Straka, H. (2008). Differential dynamic processing of afferent signals in frog tonic and phasic second-order vestibular neurons. J. Neurosci. 28, 10349-10362. doi: 10. 1523/JNEUROSCI.3368-08.2008

Precht, W., Llinás, R., and Clarke, M. (1971). Physiological responses of frog fibers to horizontal angular rotation. Exp. Brain Res. 13, 378-407. doi: 10. 1007/bf00234338

Rennie, K. J., and Correia, M. J. (1994). Potassium currents in mammalian and avian isolated type I semicircular canal hair cells. J. Neurophysiol. 71, 317-329.

Ricci, A. J., Crawford, A. C., and Fettiplace, R. (2003). Tonotopic variation in the conductance of the hair cell mechanotransducer channel. Neuron 40, 983-990. doi: 10.1016/s0896-6273(03)00721-9

Rossi, M. L., Bonifazzi, C., Martini, M., and Fesce, R. (1989). Static and dynamic properties of synaptic transmission at the cyto-neural junction of the frog labyrinth posterior canal. J. Gen. Physiol. 94, 303-327. doi: 10.1085/jgp. 94.2.303

Rossi, M. L., Martini, M., Pelucchi, B., and Fesce, R. (1994). The quantal nature of transmitter release at the cytoneural junction of the frog labyrinth. J. Physiol. 478, 17-35. doi: 10.1113/jphysiol.1994.sp020227

Rossi, M. L., Prigioni, I., Gioglio, L., Rubbini, G., Russo, G., Martini, M., et al. (2006). IP3 receptor in the hair cells of frog semicircular canal and its possible functional role. Eur. J. Neurosci. 23, 1775-1783. doi: 10.1111/j.1460-9568.2006. 04708.x

Rossi, M. L., Rubbini, G., Gioglio, L., Martini, M., and Fesce, R. (2010). Exposure to reduced gravity impairs junctional transmission at the semicircular canal in the frog labyrinth. Am. J. Physiol. Regul. Integr. Comp. Physiol. 298, R439-R452. doi: 10.1152/ajpregu.00673.2009

Russo, G., Calzi, D., Martini, M., Rossi, M. L., Fesce, R., and Prigioni, I. (2007). Potassium currents in the hair cells of vestibular epithelium: positiondependent expression of two types of A channels. Eur. J. Neurosci. 25, 695-704. doi: 10.1111/j.1460-9568.2007.05327.x

Schnee, M. E., Lawton, D. M., Furness, D. N., Benke, T. A., and Ricci, A. J. (2005). Auditory hair cell-afferent fiber synapses are specialized to operate at their best frequencies. Neuron 47, 243-254. doi: 10.1016/j.neuron.2005. 06.004

Scullin, C. S., and Partridge, L. D. (2010). Contribution of SERCA pump and ryanodine-sensitive stores to presynaptic residual $\mathrm{Ca}^{2+}$. Cell Calcium 47, 326-338. doi: 10.1016/j.ceca.2010.01.004

Soto, E., Vega, R., and Budelli, R. (2002). The receptor potential in type I and type II vestibular system hair cells: a model analysis. Hear. Res. 165, 35-47. doi: 10. 1016/s0378-5955(01)00418-x

Taglietti, V., Valli, P., and Casella, C. (1973). Discharge properties and innervation of the sensory units in the crista ampullaris. Arch. Sci. Biol. (Bologna) 57, 73-86.

Wilson, V. J., and Melvill Jones, G. (eds.) (1979). "Mechanoneural transduction and the primary afferent response," in Mammalian Vestibular Physiology (New York: Plenum Press), 77-123.

Yellen, G. (1984). Ionic permeation and blockade in $\mathrm{Ca}^{2+}$-activated $\mathrm{K}+$ channels of bovine chromaffin cells. J. Gen. Physiol. 84, 157-186. doi: 10.1085/jgp. 84.2.157

Zeddies, D. G., and Siegel, J. H. (2004). A biophysical model of an inner hair cell. J. Acoust. Soc. Am. 116, 426-441. doi: 10.1121/1.1755237

Conflict of Interest Statement: The authors declare that the research was conducted in the absence of any commercial or financial relationships that could be construed as a potential conflict of interest.

Copyright (C) 2015 Martini, Canella, Rubbini, Fesce and Rossi. This is an open-access article distributed under the terms of the Creative Commons Attribution License (CC $B Y)$. The use, distribution and reproduction in other forums is permitted, provided the original author(s) or licensor are credited and that the original publication in this journal is cited, in accordance with accepted academic practice. No use, distribution or reproduction is permitted which does not comply with these terms. 